\title{
Assessing Attachment Security With the Attachment $Q$ Sort: Meta-Analytic Evidence for the Validity of the Observer AQS
}

\author{
Marinus H. van IJzendoorn, Carolus M. J. L. Vereijken, Marian J. Bakermans-Kranenburg, and J. Marianne \\ Riksen-Walraven
}

\begin{abstract}
The reliability and validity of the Attachment $Q$ Sort (AQS; Waters \& Deane, 1985) was tested in a series of metaanalyses on 139 studies with 13,835 children. The observer AQS security score showed convergent validity with Strange Situation procedure (SSP) security $(r=.31)$ and excellent predictive validity with sensitivity measures $(r=.39)$. Its association with temperament was weaker $(r=.16)$, which supports the discriminant validity of the observer AQS. Studies on the stability of the observer AQS are still relatively scarce but they have yielded promising results (mean $r=.28 ; k=4, n=162$ ). It is concluded that the observer AQS, but not the self-reported AQS, is a valid measure of attachment.
\end{abstract}

In this article we present a series of meta-analyses on studies that apply the Attachment $Q$ Sort (AQS; Vaughn \& Waters, 1990; Waters \& Deane, 1985) to assess security of infants' and toddlers' attachment to their parents or caregivers. For 3 decades the Strange Situation procedure (SSP) has been the established measure of infants' attachment security (Ainsworth, Blehar, Waters, \& Wall, 1978). Our goal is to evaluate the reliability and validity of the AQS as an alternative instrument for the assessment of attachment security. Although a narrative approach may yield a valuable overview of AQS studies (Solomon \& George, 1999), the use of meta-analysis leads to more precise estimates of reliability and validity indicators, and to a more comprehensive view of potential moderators.

\footnotetext{
Marinus H. van IJzendoorn, Center for Child and Family Studies, Leiden University; Carolus M. J. L. Vereijken, Department of Developmental Psychology, University of Nijmegen; Marian J. Bakermans-Kranenburg, Center for Child and Family Studies, Leiden University; J. Marianne Riksen-Walraven, Department of Developmental Psychology, University of Nijmegen.

The work on this study was facilitated by a Fellowship of the Netherlands Institute for Advanced Study in the Humanities and Social Sciences to Marinus van IJzendoorn. We would like to thank Cornelis van Lieshout, Sanneke van Geest, and Rosalinda Cassibba for their valuable support in preparing this manuscript. The data on child center care in the United States were derived from the data set made available by the National Institute of Child Health and Human Development (NICHD) Early Child Care Research Network supported by NICHD through a cooperative agreement that calls for scientific collaboration between the grantees and NICHD staff. We are grateful to Sarah Friedman for her support.

Correspondence concerning this article should be addressed to Marinus H. van IJzendoorn, Center for Child and Family Studies, Leiden University, P.O. Box 9555, NL-2300 RB Leiden, The Netherlands. Electronic mail may be sent to vanijzen@fsw.leidenuniv.nl.
}

Since Bowlby's (1969) early work on the theoretical foundations of children's emotional ties to their parents, attachment theory has become a major source of hypotheses for research on the socioemotional development of young children. The growing influence of attachment theory was in large part due to the availability of a standard instrument for the assessment of infant attachment, that is, the SSP, developed by Ainsworth and her colleagues (Ainsworth et al., 1978; Ainsworth \& Wittig, 1969). In the SSP, children's attachment behavior toward a parent or caregiver is observed in a laboratory playroom where they encounter an unfamiliar adult and are twice briefly separated from their attachment figure. Although the SSP has yielded remarkable results (for reviews see Cassidy \& Shaver, 1999), it has been a drawback that attachment research was almost exclusively dependent on a single procedure for the measurement of attachment. The SSP entails an artificial and stressful laboratory procedure that has been criticized for its lack of ecological validity (Bronfenbrenner, 1979) and that has raised some ethical concerns (Thompson, 1990). Furthermore, the SSP was developed for use with infants in the 2nd year of their life, which led to the relative neglect of attachment during later stages of life.

Two decades ago, Waters and Deane (1985) inspired by the seminal work of Jack Block (1961) on the $Q$ approach-introduced another method for assessing attachment security in infants and toddlers, that is, the AQS. The AQS consists of a large number of cards $(75,90$, or 100). On each card a specific behavioral characteristic of children between 12 and 48 months of age is described. The cards can

(C) 2004 by the Society for Research in Child Development, Inc. All rights reserved. 0009-3920/2004/7504-0014 
be used as a standard vocabulary to describe the behavior of a child in the natural home setting, with special emphasis on secure-base behavior (Vaughn \& Waters, 1990). After several hours of observation the observer ranks the cards into several piles from "most descriptive of the subject" to "least descriptive of the subject." The number of piles and the number of cards that can be put in each pile are fixed. By comparing the resulting description with the behavioral profile of a prototypical secure child as provided by several experts in the field of attachment theory, a score for attachment security can be derived. In fact, the AQS security score is the correlation between the $Q$ sort of this specific child and the expert sort describing the prototypically secure child. In theory, AQS scores may range from -1.0 to +1.0 , that is, from a perfect negative correlation to a perfect positive correlation with the ideal-type security sort. To single or average AQS scores no specific meaning can be attached other than the degree of similarity to the ideal-type security sort. There is no natural cutoff point dividing secure from insecure children.

Without denying the numerous strengths of the SSP, the AQS has some advantages over the SSP. First, it can be used for a broader age range (12-48 months) than the SSP. Moreover, AQS observations are conducted in the home, and they may therefore have higher ecological validity. Furthermore, because the application of the AQS does not require the stressful separations used in the SSP, the method can be applied in cultures and populations in which parent-infant separations are uncommon (e.g., Kazui, Endo, Tanaka, Sakagami, \& Suganuma, 2000). Because the AQS is less intrusive than the SSP, it may be used more frequently with the same child, for example, in repeated measures designs and in studies on children's attachment networks. Finally, the application of the AQS in divergent cultures or populations may be attuned to the specific prototypical secure-base behavior of the children from those backgrounds (Posada, Gao, et al., 1995). The AQS may even be used to assess infant security in extremely disturbed groups such as autistic children (Rutgers, Bakermans-Kranenburg, \& Van IJzendoorn, 2004) and in nonhuman primates such as Old World monkeys (Kondo-Ikemura \& Waters, 1995). It should however be noted that the AQS is time consuming, its observational database usually is not videotaped for archival purposes and for review, and it fails to differentiate between types of insecurity.

Obviously, if the AQS is a valid instrument for the assessment of attachment security, it would be an important addition to the attachment researcher's tool box. Waters and Deane (1985) have extensively discussed item content and sorting procedure of the AQS and concluded that both are appropriate for the measurement of the concept of attachment, thus supporting its content validity. The present study focuses on the empirical results that have been obtained with the AQS. Three types of validity are discussed. First, convergent validity of the AQS indicates the degree to which it is related to instruments measuring the same construct. In particular, AQS-derived attachment security should be correlated with security classifications based on behavior in the SSP. A recently emerging issue pertains to the association between the AQS and disorganized attachment (Lyons-Ruth \& Jacobvitz, 1999; Main \& Solomon, 1990; Van IJzendoorn, Schuengel, \& Bakermans-Kranenburg, 1999). Although the AQS has not been developed to assess disorganization of attachment, its broad spectrum of behavioral descriptors might reflect differences between disorganized and nondisorganized children. In particular, the hypothesis may be tested that disorganized attachment is indexed by the most extreme scores on the AQS (E. Waters, personal communication, June 19, 2002). Second, the AQS as a procedure to assess attachment security should demonstrate discriminant validity; that is, it should only weakly be related to instruments that have proved to measure other constructs such as temperament (Sroufe, 1985; Vaughn \& Bost, 1999). Although attachment behavior and temperament may be related, in particular with increasing age (Vaughn et al., 1992), the two constructs should at the same time be considered as conceptually separate components of the children's socioemotional development. From a behavioral genetics perspective, attachment security and temperamental reactivity have been documented to have different roots (environmental influences vs. heritability; see Bokhorst et al., 2003). Third, the AQS shows predictive validity if AQS security is related to other constructs as predicted by attachment theory. Two central propositions of attachment theory imply that children's attachment security is related to their caregiver's sensitive responsiveness and to social competence, in particular, in close (friendship) relationships. Children's attachment security is assumed to be the outcome of interactions with their social environment, in particular, with their primary caregivers. In fact, the caregiver's ability to perceive the child's attachment signals accurately and to respond adequately and promptly to these signals are assumed to be two of the most important determinants of the child's attachment security (Ainsworth et al., 1978). The association between attachment and sensitive responsiveness is clearly supported by correlational and experimental evidence (for meta-analytic 
reviews, see De Wolff \& Van IJzendoorn, 1997; Bakermans-Kranenburg, Van IJzendoorn, \& Juffer, 2003). Furthermore, attachment security is assumed to predict the child's later socioemotional development. Although the causal mechanisms are still being debated (Lamb \& Nash, 1989; Thompson, 1999) and the influence of attachment may be restricted to social competence in intimate relationships (Sroufe, 1988), support has been found for associations with children's social competence in interaction with peers, strangers, and parents (Cohn, Patterson, \& Christopoulos, 1991; Elicker, Englund, \& Sroufe, 1992; Schneider, Atkinson, \& Tardif, 2001; Thompson, 1999). Because the link with social competence in peer relations has also been investigated in several AQS studies, we focus on this dimension of socioemotional development in the current meta-analytic study.

Besides convergent, discriminant, and predictive validity, the AQS should also show intercoder reliability and some stability across time. In stable circumstances, attachment security as assessed in the SSP shows considerable stability across 3 to 6 months (Bretherton, 1985; Lamb, Thompson, Gardner, \& Charnov, 1985). Recently, new measures of attachment security for preschoolers and older children have also shown considerable stability of attachment patterns across the preschool period (Howes \& Hamilton, 1992b; Main \& Cassidy, 1988; StevensonHinde \& Verschueren, 2002; Solomon \& George, 1999). It has been claimed that instability of attachment security may be due to life events and changes in life circumstances that influence the caregiver's sensitive responsiveness (Lamb et al., 1985; Vaughn, Egeland, Sroufe, \& Waters, 1979). However, across the board, stability studies of attachment security have shown considerable continuity across the first 20 years of life (Fraley, 2002; Waters, Hamilton, \& Weinfield, 2000), and alternative attachment measures such as the AQS should also document some stability across time.

There are some additional issues that should be considered in evaluating the AQS as a measure for security of attachment. Children can be attached to their mother and to their father, but also to their day care providers. The child's security in these relationships has been described with the AQS in several studies. It is assumed that the theoretical associations described previously should hold true for each of the attachment relationships of the child, irrespective of the biological status of the attachment figure (Howes, 1999).

A further issue pertains to the sorter of the AQS. The AQS can be used to describe the child's attachment relationship by trained observers, but also by the parent or caregiver who is part of the relationship. Because in both cases the same attachment relationship is described they should yield similar results. There are, however, some reasons why these $Q$ sorts may diverge. The presence of the observer in the family may influence the parent-child interaction. The amount of time an observer can spend with the family is limited, and so is his or her access to attachment-relevant situations and events. The caregiver may, however, be more subject to response biases because of the own involvement in the attachment relationship. For these reasons, AQSs sorted by caregivers and by observers may diverge in terms of validity characteristics.

Since the first publication on the AQS in 1985 (Waters \& Deane, 1985) the Q-sort cards, data-collection procedures, and scoring methods have been revised. The initial AQS consisted of 100 items, but later 75- and 90-item versions were composed. Waters and Deane (1985) proposed an extensive procedure to collect observer $Q$ sorts, using free observation of parent-child interaction in the home. Several studies, however, used more structured and time-limited procedures and home visits. These procedural aspects of the AQS may influence the validity of the AQS. We examine these issues in our metaanalyses.

In sum, we tested the following hypotheses. First, we examined the convergence between attachment security as assessed in the SSP and through the AQS, and we expected to find a strong association (convergent validity). In addition, children classified as disorganized in the SSP were expected to have extremely low AQS security scores. Second, attachment security and temperament have been documented to be unrelated. The relation between AQS security and temperamental characteristics should therefore be weak or absent to show discriminant validity. Only with increasing age, attachment and temperament may become more related (Vaughn \& Bost, 1999). Third, one of the core assumptions in attachment theory is the crucial role of parental sensitivity in the development of attachment. We tested whether more AQS security was associated with more sensitivity of the parent (predictive validity). Fourth, although subject of considerable debate, it is widely assumed that attachment security should be related to the child's behavior in (intimate) relationships outside of the family. We examined AQS studies on children's socioemotional development and tested whether AQS security was associated with more social competence (predictive validity). Finally, we tested whether the self-reported AQS showed validity indicators comparable to those of the time-consuming observer 
AQS and thus whether it can be used as a viable alternative to the observer AQS.

\section{Method}

\section{Selection of Studies}

Studies were included in this meta-analytic investigation if they satisfied two criteria. First, the study should report results of analyses with the AQS. Second, the report should contain sufficient information on data collection to evaluate the study, such as the specific version of the AQS, the number of participants, and participants' age. A literature search was conducted using the following computerized databases: PsychLIT, ERIC, Sociofile, and Dissertation Abstracts. The ISI database of social science citations (Web of Science) was searched for references to the papers presenting the AQS (Vaughn \& Waters, 1990; Waters \& Deane, 1985; Waters, Vaughn, Posada, \& Kondo-Ikemura, 1995). The references in the studies found in the computerized searches were then checked for other relevant studies. Because the most recent studies may not yet be included in these databases, manual searches of recent journals on child development were also conducted. Finally, colleagues provided us with several manuscripts that are still under review or in press. We included published as well as unpublished papers. In the meta-analytic literature the inclusion of unpublished material is recommended to protect against the file-drawer risk, that is, the potential presence of unpublished manuscripts with null results in the file drawers of disappointed researchers (e.g., Light \& Pillemer, 1984; Mullen, 1989).

The literature search yielded 137 studies with 13,835 children. Some studies did not contain sufficient information regarding sample size or sorter (observer or caregiver), and they could not be included in the meta-analyses. In some cases, two or more articles reported on the same sample. In these cases, the results of the papers were treated as belonging to one empirical study. In some other cases, more samples were described in one paper. The samples were considered as separate studies (see Vaughn et al., 1992). Four studies drew on participants from two nonoverlapping samples (Howes \& Hamilton, 1992a, 1992b; Howes, Hamilton, \& Matheson, 1994; Howes, Matheson, \& Hamilton, 1994). If studies contained two or more statistics for the same association, these statistics were meta-analytically combined within the study (with Borenstein, Rothstein, \& Cohen's, 2000, Comprehensive MetaAnalysis [CMA] program; see the discussion in the
Statistical Analyses section), and only the combined statistic was included in the meta-analysis.

Of the 139 samples, 80 were conducted on the North American continent. Mothers described the attachment relationship with their child in 77 studies, fathers did so in 10 studies, and day care teachers did so in 2 studies. Trained observers described attachment to mother in 54 studies, attachment to the father in 1 study, and attachment to a day care teacher in 15 studies. Sample size varied from 7 children in the smallest sample (Petrie \& Davidson, 1995) to 3,060 children in the largest sample (Howes \& Ritchie, 1999). Sufficient numbers of studies were available for testing the association between AQS and SSP $(k=32)$, AQS and sensitive responsiveness $(k=42), \mathrm{AQS}$ and temperament $(k=27)$, and AQS and socioemotional development $(k=33)$. Earlier meta-analyses in the area of attachment were based on similar or smaller numbers of studies (e.g., Fox, Kimmerly, \& Schafer, 1991; Goldsmith \& Alansky, 1987; Van IJzendoorn, 1995).

\section{Coding System}

A coding system was used to rate every AQS study on design, sample, and publication characteristics. As design characteristics we coded sample size, sorter, AQS version, duration, and interval. We coded whether the AQS was sorted by a trained observer or by the attachment figure who was part of the relationship that was assessed with the AQS (mother, father, or day care teacher). We also coded whether the AQS version with 75,90 , or 100 items had been used in the study, or whether an attachment measure was based on a selection of AQS items. For the duration of AQS observations the total observation time was coded; for example, when the AQS sorting was based on two observations of $2 \mathrm{hr}$ each, the duration of the observation was fixed at $240 \mathrm{~min}$. Concerning interval, we coded the intervening period between the AQS and the assessment of the other variable(s); this period ranged from 0 months (e.g., in Stevenson-Hinde \& Shouldice, 1990, the AQS was sorted within 1 month from the temperament assessment) to 24 months (in Schmidt, 1998, the AQS was sorted at 36 months of the child's age, and socioemotional development was assessed at 60 months). Moreover, we coded which other relevant variables were measured (attachment in the SSP, temperament, sensitive responsiveness, or the child's socioemotional development). For attachment in the SSP, we noted whether children had been classified with the three-way coding system (Ainsworth et al., 1978) or with the four-way coding 
system, including disorganized attachment behavior (Main \& Solomon, 1990). For temperament, we selected indicators of temperamental reactivity or related temperamental dimensions such as irritability or mood. Sensitive responsiveness referred to the mother's sensitivity as assessed with, for example, the Maternal Behavior $Q$ Set (Pederson et al., 1990) or the rating scales of Ainsworth, Bell, and Stayton (1974). Indicators for the child's socioemotional development were the Child Behavior Checklist (CBCL; Achenbach, 1985) and social competence in relation to peers (e.g., in Denham et al., 2001). As sample characteristics we coded the age of the child when the AQS was sorted, whether the sample was clinical or nonclinical, and the country of the sample (United States, Canada, Europe, or other). Finally, we coded the type of publication (journal, book chapter, dissertation, or conference presentation). The studies were coded by Marinus van IJzendoorn and Marian J. Bakermans-Kranenburg. The intercoder reliability of the coding system was established on 22 studies. Reliabilities ranged from .94 to 1.00 .

\section{Statistical Analyses}

In the present meta-analyses the procedures developed by Rosenthal (1991), Mullen (1989), and Borenstein et al. (2000) were applied. The statistical tests of the pertinent studies were transformed into a common metric for effect size: the correlation coefficient $(r)$. Potential moderator variables were examined to test whether they significantly explained the variability of the effect sizes. Moderators were: type of publication, country, participants' age at the time of the AQS assessment, version of AQS, sorter (observer or caregiver), hours of observation for AQS assessment, intervening period between AQS assessment and pertinent other variable, and type of sample (nonclinical or clinical). The extremely large sample size of the National Institute of Child Health and Human Development (NICHD) Early Child Care Research Network (1999) study $(n=1,148)$ was winsorized (i.e., $n=250$ ) in the weighting function to prevent the results from being unduly determined by only one outlying study (Hampel, Ronchetti, Rousseeuw, \& Stahel, 1986). Similarly, the large sample size of Howes and Ritchie's (1999) study on caregiver-child attachments was winsorized $(n=$ $500)$ in the analyses on social competence. No outlying effect sizes $(z<-3.26$ or $z>3.26$; Tabachnik \& Fidell, 2001) were detected in any of the meta-analytic data sets after conversion into Fisher Z. Analyses were performed with Mullen's (1989) statistical package Advanced BASIC Meta-Analysis and with
Borenstein et al.'s (2000) CMA program. Inversevariance-weighted analyses were conducted throughout, in which correlations were transformed to Fisher $Z$; for the algorithm used in the final analyses, see Borenstein and Rothstein (1999, p. 270 ff).

Tests for homogeneity of study results were applied to check whether such results were sampled from different populations. Borenstein et al.'s (2000) CMA program computed fixed as well as randomeffect model parameters. Significance tests and moderator analyses in fixed-effects models are based on the assumption that differences between studies leading to differences in effects are not random and that, in principle, the set of study effect sizes is homogeneous at the population level. Significance testing is based on the total number of participants, but generalization is restricted to other participants that might have been included in the same studies of the meta-analysis (Rosenthal, 1995). In random-effects models, significance testing is based only on the total number of studies and generalization is to the population of studies from which the current set of studies was drawn (Rosenthal, 1995).

It has been argued that random effects models more adequately mirror the heterogeneity in behavioral studies and use noninflated alpha levels when the requirement of homogeneity has not been met (Hedges \& Olkin, 1985). We decided to present the combined effect sizes and their confidence intervals (CIs) in the context of fixed- or randomeffects models depending on the outcome of the pertinent homogeneity test; that is, we presented fixed-effect sizes and their CIs only when the homogeneity test did not demonstrate heterogeneity. The $Q$ statistics are presented to test the homogeneity of the specific set of effect sizes and to test the significance of moderators (Borenstein et al., 2000; Mullen, 1989; Rosenthal, 1995). In our series of metaanalyses, several data sets were heterogeneous. In those cases, the random-effects model parameters (significance, CIs) are more conservative than the fixed-effects parameters, and the moderator tests (based on the fixed effects) should be considered to be descriptive of the specific set of studies at hand and should be interpreted with caution (Rosenthal, 1995). In the two largest meta-analyses (on the associations between AQS and SSP, and AQS and sensitivity), we conducted a multivariate regression analysis with the most relevant moderators (age, duration, and country) as predictors to test whether they predicted nonoverlapping variance. Effect sizes ( $r$ ) were transformed into Fisher $Z$ scores because the metric of $r$ becomes nonlinear at its extreme values, and the Fisher $Z$ transformation represents a 
solution to this skewness (Mullen, 1989; Rosenthal, 1991).

To test the difference of observed security scores in normal versus clinical samples, we reconstructed the raw data for the participants in each study (providing these participants with the mean value for the sample as the best estimate of their score, except for the large NICHD study, 1999, for which the individual scores were available), and we computed the $t$ statistic for the difference between the two groups.

\section{Results}

\section{Mean Security Scores}

An overview of the studies is presented in Table 1. In 34 samples $(n=2,703)$ the AQS for the attachment relationship with the mother was sorted by an observer. The mean security score of these studies was $.31(S D=.16)$. The mean security score of .21 $(S D=.08)$ in clinical samples $(k=6, n=187)$ was significantly lower than the mean security score of $.32(S D=.16)$ in normal samples $(k=28, n=2,516)$, $t(297.20)=16.06, p<.01 \quad$ (effect size $r=.30$ ). Of course, the standard deviations underestimated the real standard deviation in the specific study, but the mean value across studies was exact, and the test would be significant even if the standard deviations were much larger.

\section{Association Between the AQS and the SSP: Convergent Validity}

Total set of AQS studies. In 32 samples $(n=1,981)$, AQS security was related to attachment security derived from the SSP (see Table 2). The combined effect size amounted to $r=.23$, which indicated a moderate association between the AQS and the SSP in the expected direction. However, the observer AQS outcomes $(k=17, n=1,070)$ differed significantly from the self-reported AQS $(k=15, n=911)$. The self-reported AQS security was only weakly related to attachment security as derived from the SSP $(r=.14)$, whereas the observer version of the AQS correlated substantially $(r=.31)$. The difference between the effect sizes of these two subsets of study outcomes was significant, $Q(d f=1)=9.25, p<.01$. From these results, we concluded that the observer AQS showed substantial but modest convergent validity as a measure for security of attachment.

AQS security has been related to disorganized attachment in five studies (Atkinson et al., 1999; NICHD Early Child Care Research Network, 1999; Seifer, Schiller, Sameroff, Resnick, \& Riordan, 1996; Van Bakel \& Riksen-Walraven, in press; Vittorini,
2002). All five studies used the observer version of the AQS. Disorganized attachment in the SSP appeared to be related to extremely low AQS scores; the significant combined effect size was $r=.35$ for the distinction between disorganized and nondisorganized attachments (see Table 2). Exploring moderators of the association between AQS security and SSP security, we focused on the observer version of the AQS.

Moderators of the association between the observer $A Q S$ and the SSP. The effect sizes of the studies on the association between the observer AQS and the SSP were heterogeneous, $Q(d f=16)=57.57, p<.01$. Significant moderators were duration of the AQS observations, age of the children, and country in which the study had been conducted. Studies with AQS observations that took longer than $3 \mathrm{hr}$ per child (at least one morning or afternoon session) showed significantly larger effect sizes for the association between AQS security and SSP security (combined $r=.42$ ) than did studies with $3 \mathrm{hr}$ or less observational time $(r=.23)$ (see Table 2). Furthermore, the observer AQS was more valid for younger children $(r=.34$ for children younger than 18 months) than for older children ( $r \mathrm{~s}=.22$ and .26 for children between 19 and 30 months and children older than 30 months, respectively). The AQS studies conducted in the United States appeared to show much less strong associations between AQS security and SSP security $(r=.14)$ than studies conducted in Canada $(r=.54)$ or in Europe $(r=.40)$. For the association between AQS and SSP, it did not matter whether the study was published in a refereed journal or otherwise, whether a clinical sample was selected or a sample with nonclinical children, what AQS version was used (90-item version vs. the other versions), or what interval existed between the assessment with the AQS and with the SSP.

\section{Association Between the AQS and Temperament: Discriminant Validity}

Total set of AQS studies. In 27 samples $(n=2,032)$ AQS security was related to temperamental reactivity or related temperamental dimensions such as mood (see Table 3). The combined effect size amounted to $r=.29$, which indicated a substantial negative association between the AQS security and temperamental reactivity. As expected, more attachment security was associated with less reactivity. However, the observer AQS outcomes $(k=10$, $n=831)$ differed significantly from the self-reported AQS $(k=17, n=1201)$. The observer AQS security was only modestly related to reactivity $(r=.16)$, 
1194 Van IJzendoorn, Vereijken, Bakermans-Kranenburg, and Riksen-Walraven

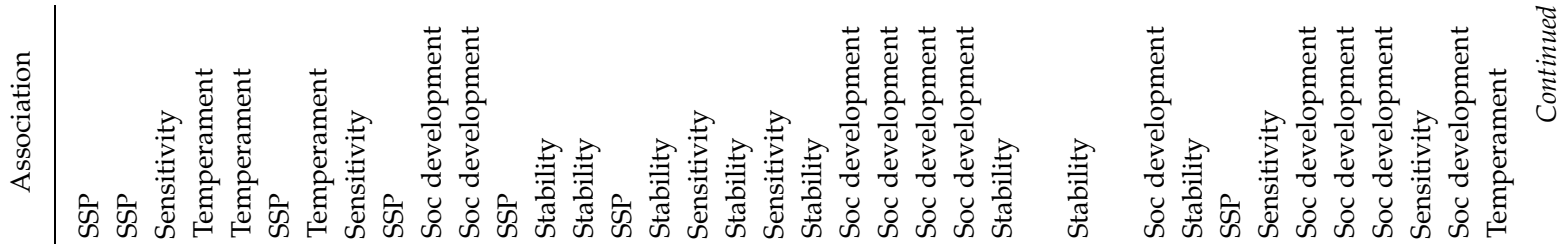

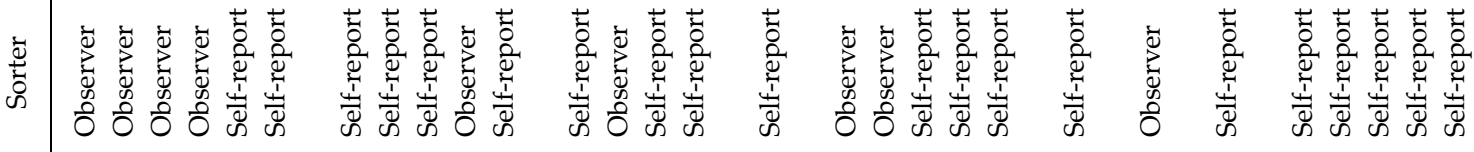

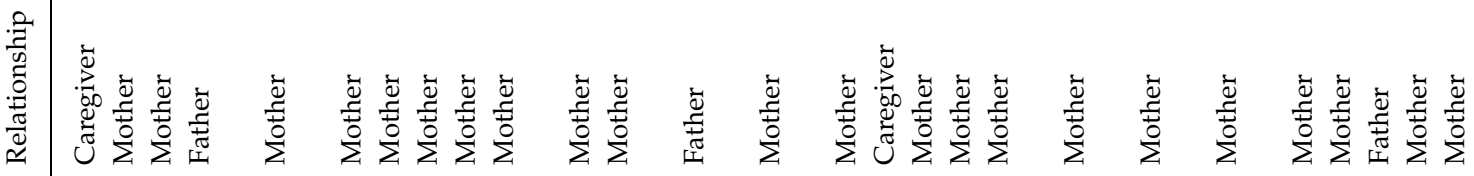

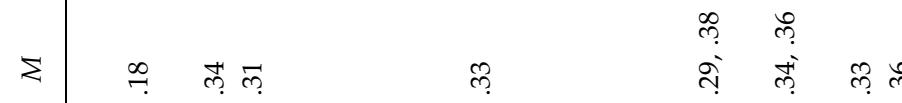

ஓे. क्षे

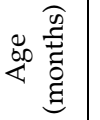

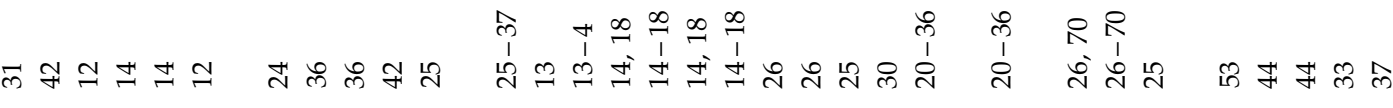

के .

z
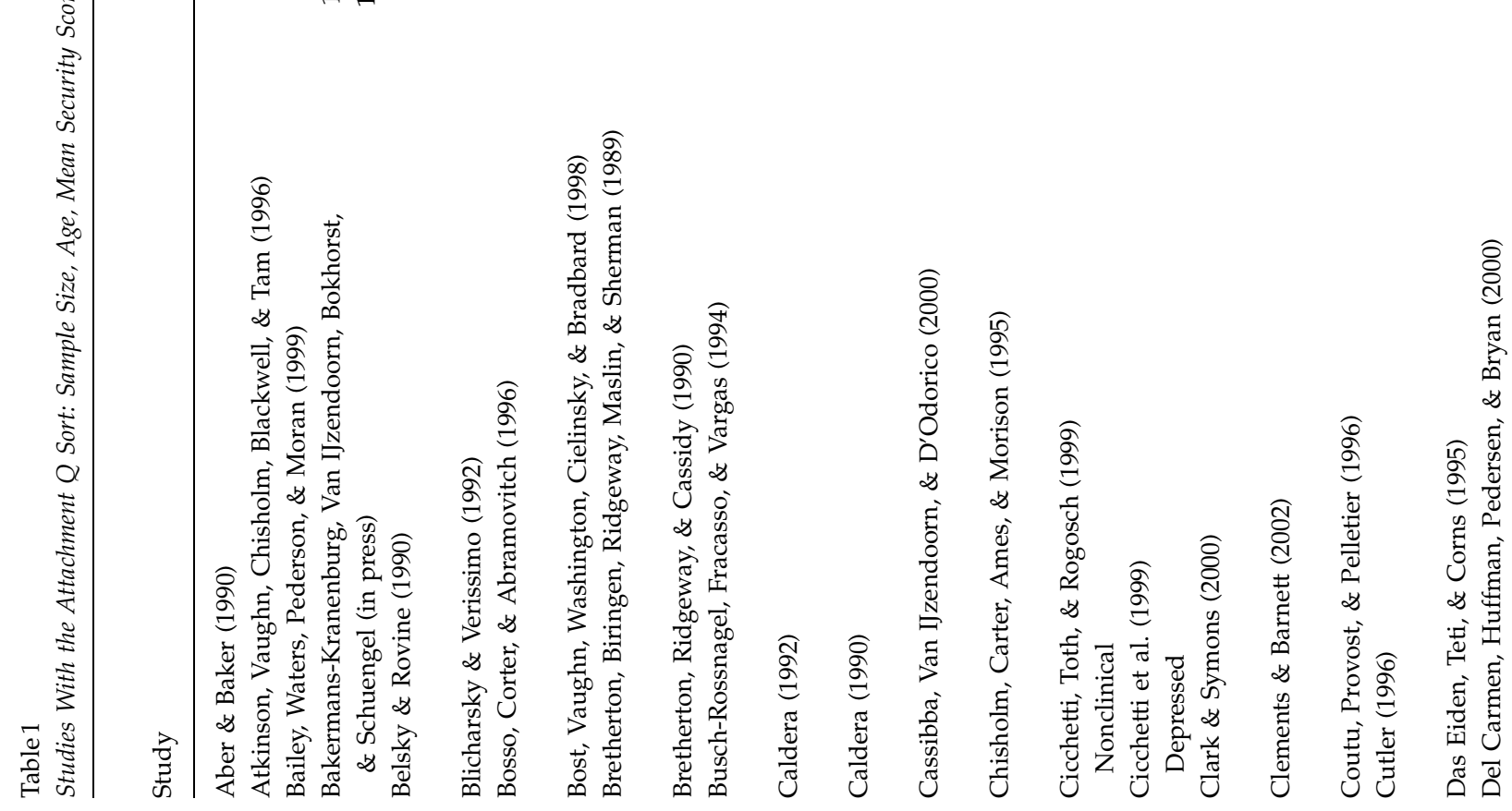


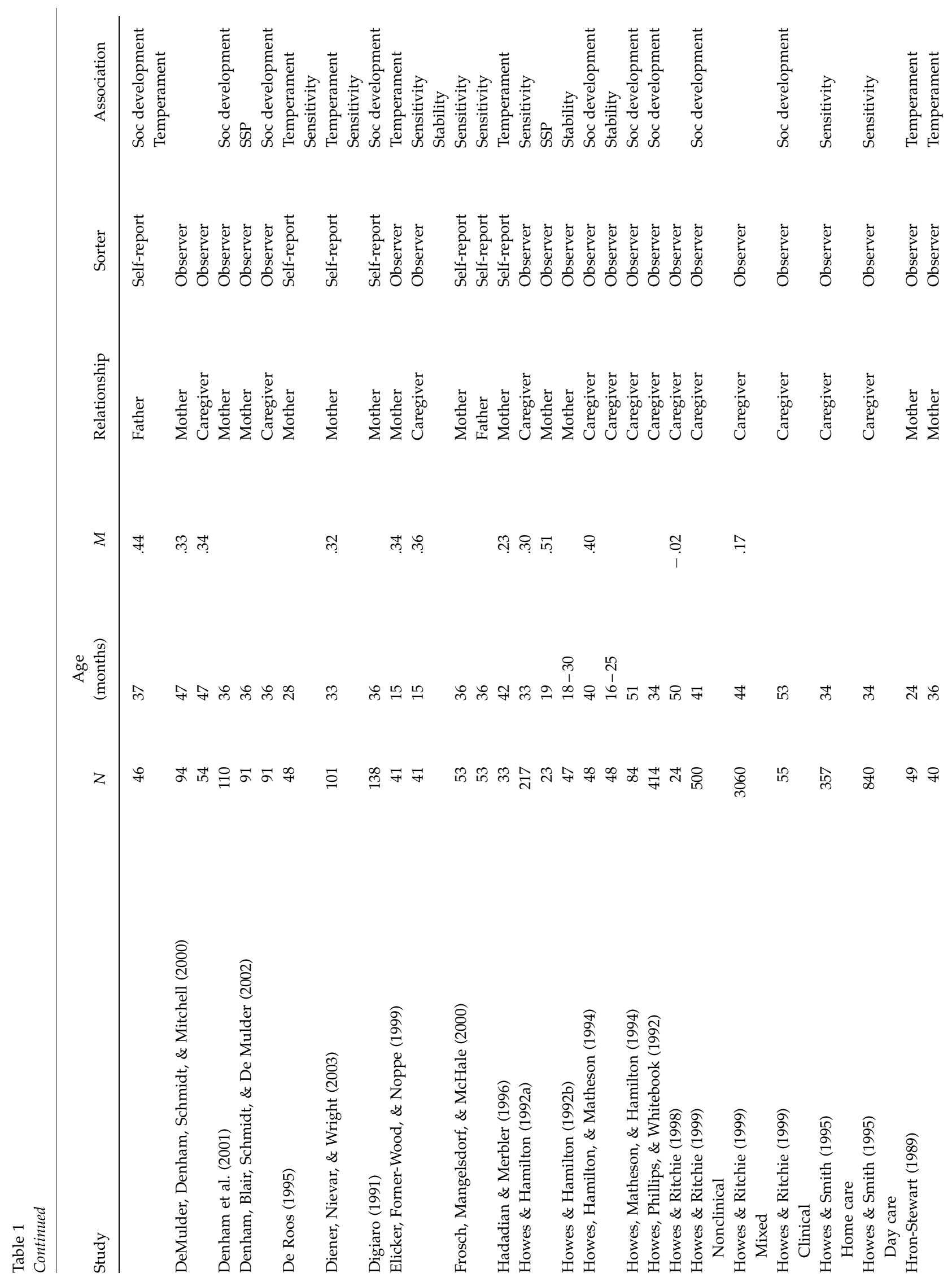


1196 Van IJzendoorn, Vereijken, Bakermans-Kranenburg, and Riksen-Walraven

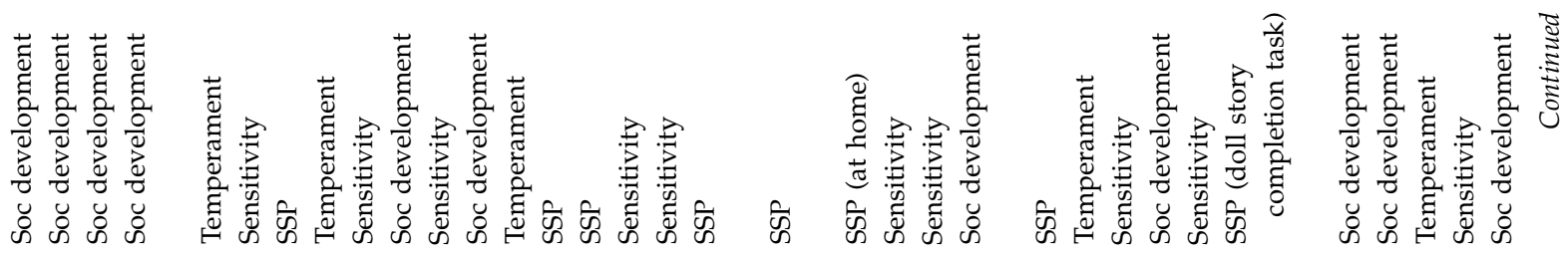

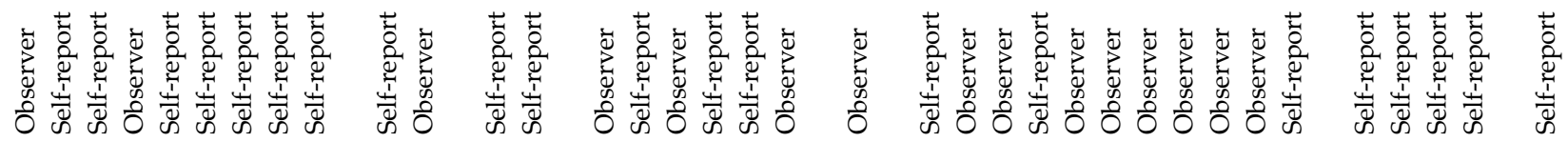

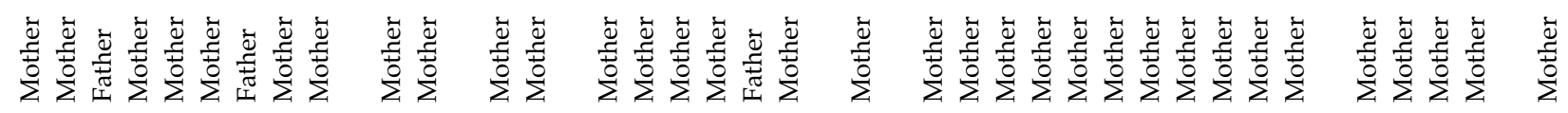

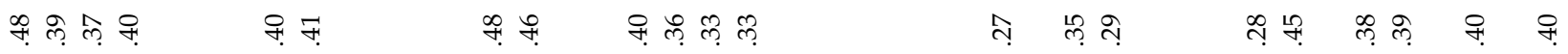

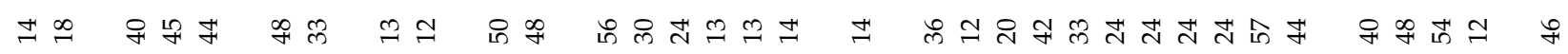

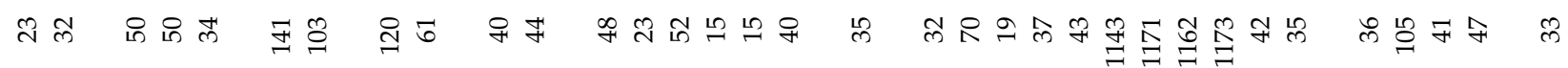

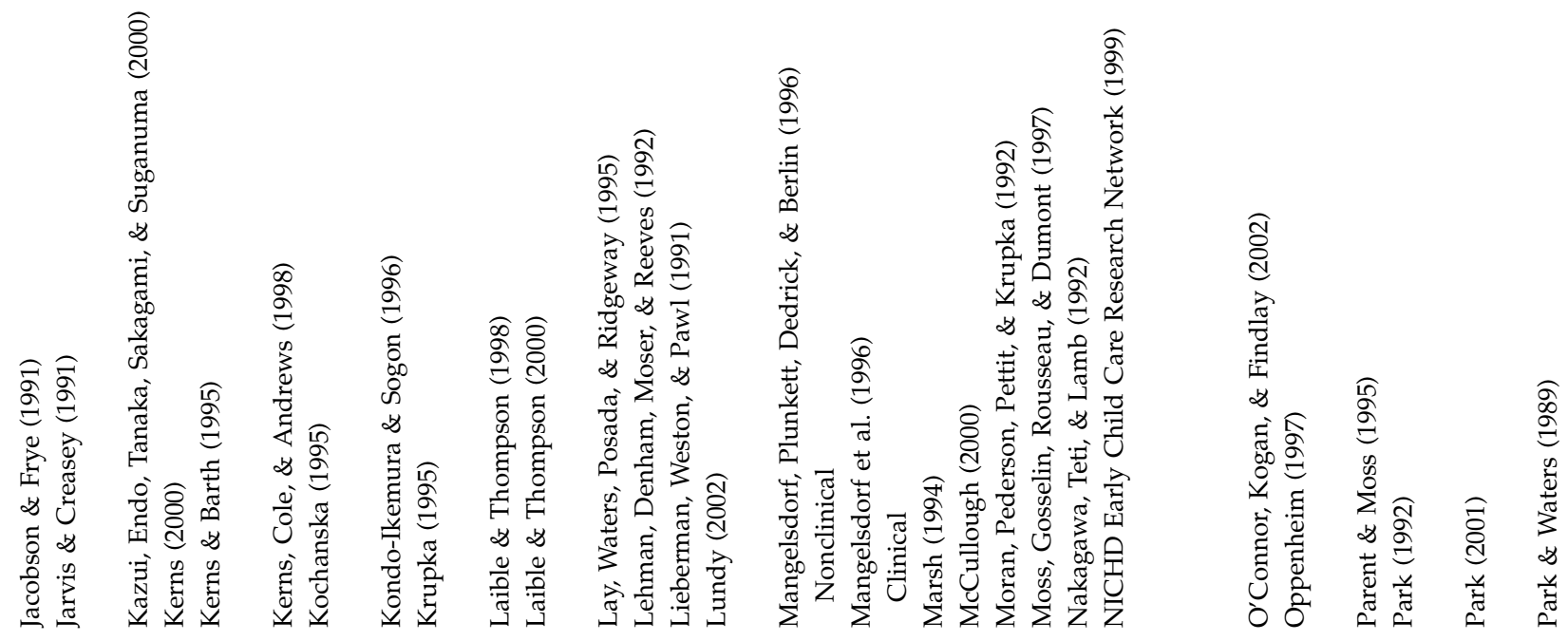




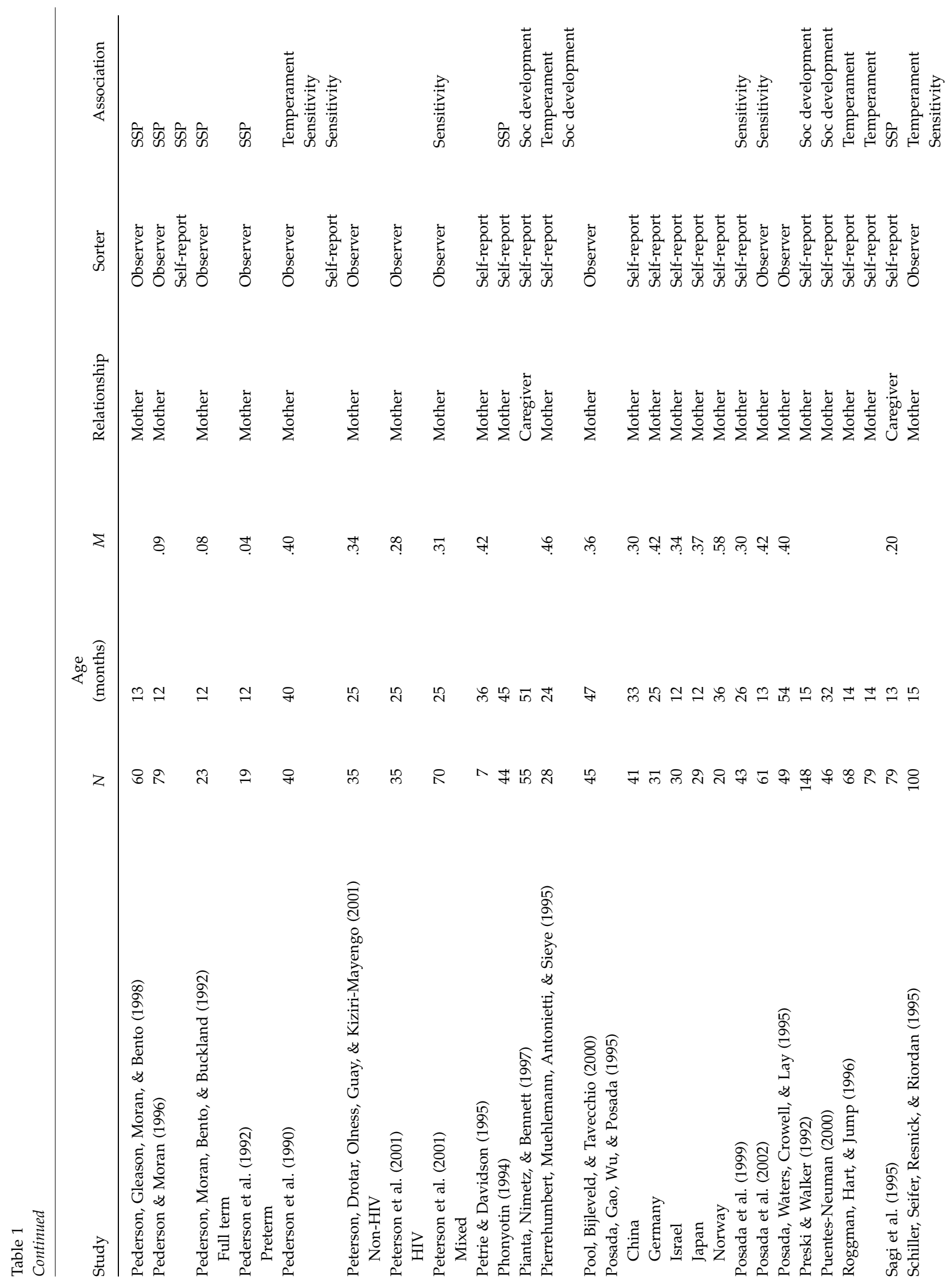


1198 Van IJzendoorn, Vereijken, Bakermans-Kranenburg, and Riksen-Walraven
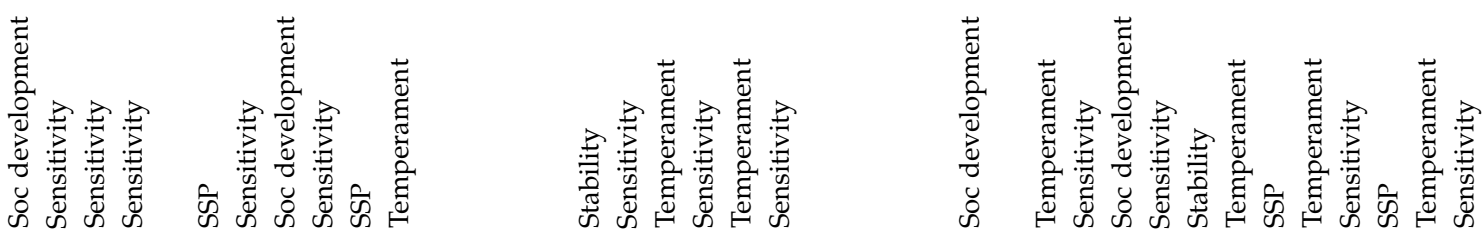

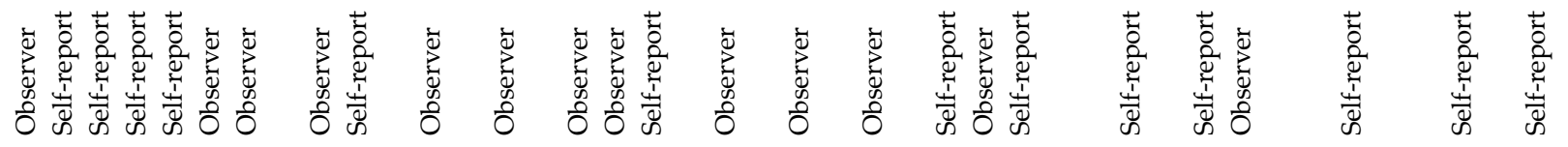

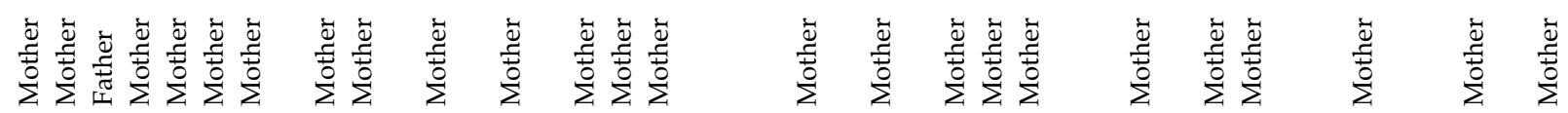

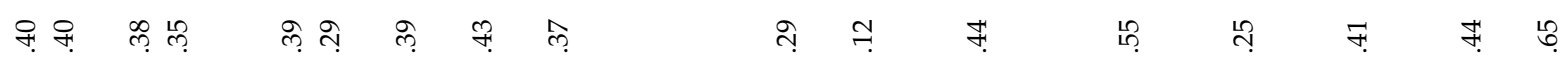

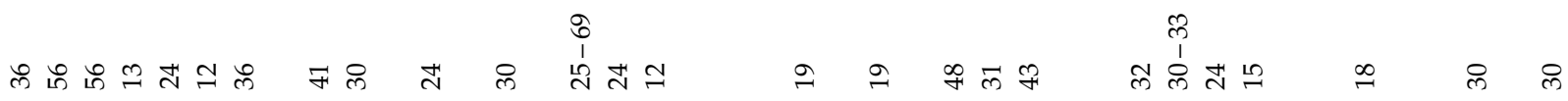

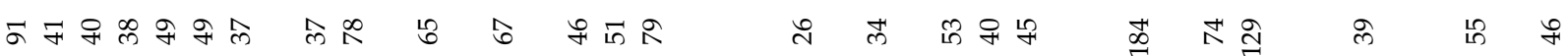

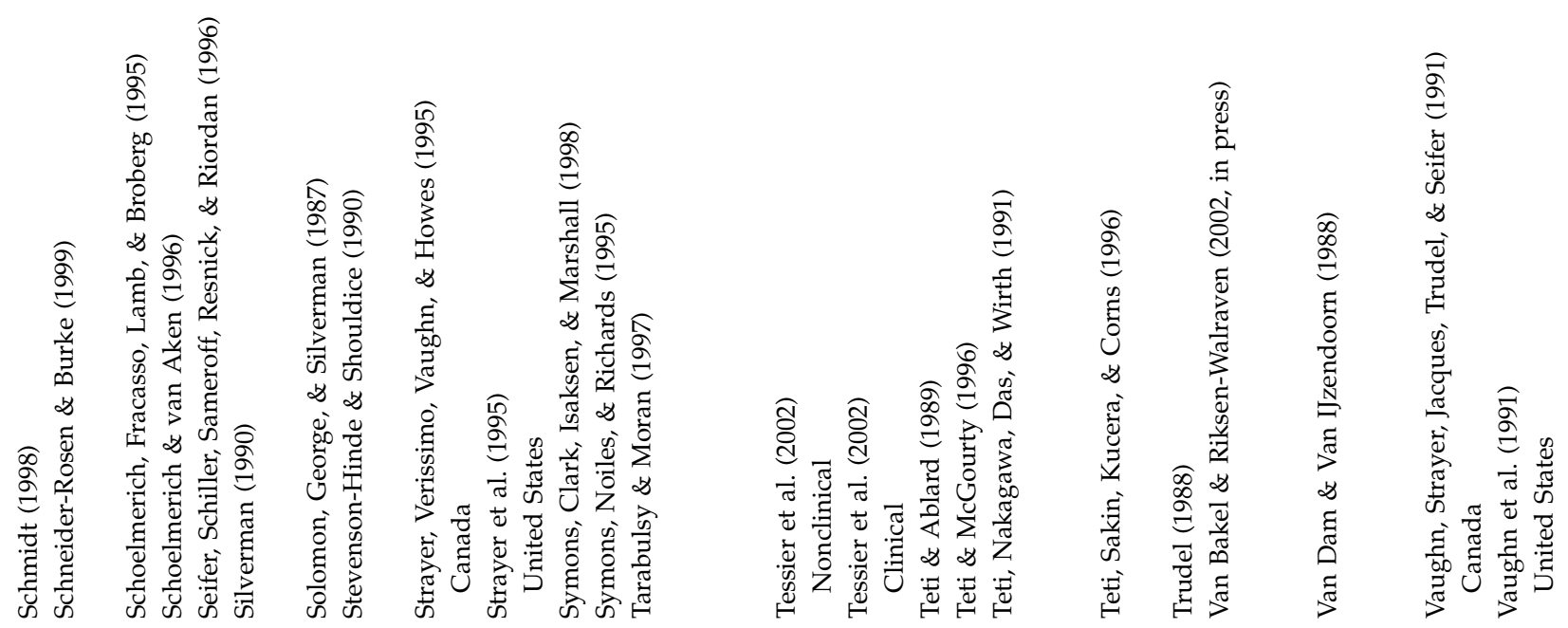




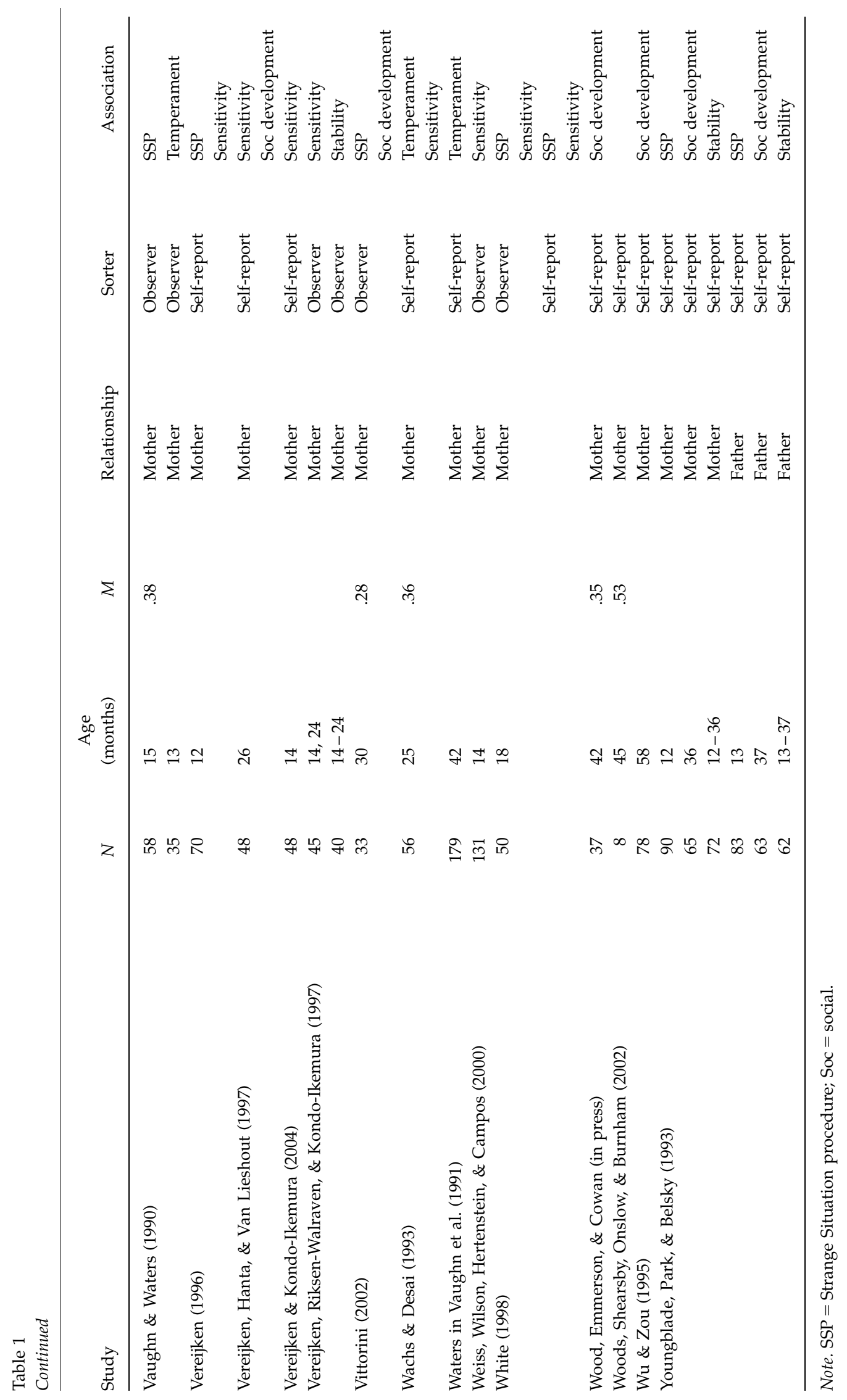


Table 2

Meta-Analytic Associations Between AQS Security and SSP Security $(k=32)$

\begin{tabular}{|c|c|c|c|c|c|c|}
\hline & $k$ & $N$ & $r$ & $95 \% \mathrm{CI}$ & $Q$ & $p$ \\
\hline Total set & 32 & $1,981^{\mathrm{a}}$ & $.23^{* *}$ & $(.14 \sim .31)$ & 99.24 & $<.01$ \\
\hline Mother & 15 & 911 & $.14^{*}$ & $(.03 \sim .23)$ & 30.30 & $<.01$ \\
\hline Observer & 17 & 1,070 & $.31^{* * *}$ & $(.19 \sim .42)$ & 57.57 & $<.01$ \\
\hline ANOVA contrast & & & & & 9.25 & $<.01$ \\
\hline SSP disorganization & 5 & 497 & $.35^{*}$ & $(.05 \sim .58)$ & 30.56 & $<.001$ \\
\hline \multicolumn{7}{|l|}{ AQS (observed) } \\
\hline AQS version & & & & & 0.18 & .67 \\
\hline 90 items & 14 & 946 & $.33^{* * *}$ & $(.19 \sim .45)$ & $54.86^{* * *}$ & \\
\hline Other & 3 & 124 & $.24^{* *}$ & $(.06 \sim .40)$ & 4.70 & \\
\hline Duration $^{\mathrm{b}}$ & & & & & 8.52 & .004 \\
\hline $180 \mathrm{~min}$ or less & 8 & 630 & $.23^{*}$ & $(.03 \sim .41)$ & $34.05^{* *}$ & \\
\hline More than $180 \mathrm{~min}$ & 7 & 338 & $.42^{* * *}$ & $(.24 \sim .57)$ & $16.70^{*}$ & \\
\hline Interval & & & & & 2.49 & .11 \\
\hline 1 month or less & 9 & 500 & $.30^{* * *}$ & $(.15 \sim .43)$ & $19.91^{*}$ & \\
\hline More than 1 month & 8 & 570 & $.33^{* *}$ & $(.11 \sim .52)$ & $37.34^{* * *}$ & \\
\hline \multicolumn{7}{|l|}{ Sample } \\
\hline Age & & & & & 13.30 & .001 \\
\hline$<18$ months & 11 & 582 & $.34^{* * *}$ & $(.18 \sim .47)$ & $33.81^{* * *}$ & \\
\hline $19-30$ months & 4 & 358 & .22 & $(-.03 \sim .45)$ & $8.91^{*}$ & \\
\hline$>30$ months & 2 & 129 & $.26^{* *}$ & $(.09 \sim .42)$ & 3.52 & \\
\hline Clinical & & & & & 0.14 & .71 \\
\hline Yes & 3 & 92 & $.23^{*}$ & $(.02 \sim .42)$ & 5.43 & \\
\hline No & 14 & 978 & $.32^{* * *}$ & $(.19 \sim .44)$ & $54.18^{* * *}$ & \\
\hline Country & & & & & 37.95 & $<.001$ \\
\hline United States & 10 & 691 & $.14^{* * *}$ & $(.06 \sim .21)$ & 12.90 & \\
\hline Canada & 5 & 219 & $.54^{* * *}$ & $(.44 \sim .63)$ & 7.48 & \\
\hline Europe & 2 & 160 & $.40^{* * *}$ & $(.26 \sim .52)$ & 1.41 & \\
\hline \multicolumn{7}{|l|}{ Publication } \\
\hline Medium & & & & & 2.55 & .11 \\
\hline Journal & 11 & 568 & .29 & $(.14 \sim .43)$ & $31.16^{* * *}$ & \\
\hline Other & 6 & 502 & $.34^{* *}$ & $(.10 \sim .55)$ & $26.03^{* * *}$ & \\
\hline
\end{tabular}

Note. $\mathrm{AQS}=$ Attachment $Q$ Sort; $\mathrm{SSP}=$ Strange Situation procedure; $\mathrm{CI}=$ confidence interval.

${ }^{a}$ The NICHD Early Child Care Research Network (1999) study was winsorized $(n=250)$.

${ }^{\mathrm{b}}$ Two studies were excluded because of missing information.

${ }^{*} p<.05 .{ }^{* *} p<.01 .{ }^{* * *} p<.001$.

whereas the self-report version of the AQS correlated strongly $(r=.35)$. The difference between the effect sizes of these two subsets of study outcomes was significant, $Q(d f=1)=20.99, p<.01$. Therefore, the observer version of the AQS showed the most discriminant validity and was used to explore moderator influences.

Moderators of the association between the observer $A Q S$ and temperamental reactivity. The effect sizes of the studies on the association between the observer AQS and reactivity were homogeneous, $Q(d f=9)=$ $16.35, p=.06$. Only one moderator was significant: Longer duration of AQS observations was related to larger effect sizes (combined $r=.26$ ) than were shorter duration of observations $(\leq 3 \mathrm{hr}$, combined $r=.11$ ). No other moderators were significant. Because of the restricted number of studies, we were not able to test the Vaughn et al. (1992) finding that the association between attachment security and temperament was stronger in older children than in younger children.

Association Between the AQS and Maternal Sensitive Responsiveness: Predictive Validity

Total set of AQS studies. In 42 samples $(n=2,768)$ AQS security was related to maternal sensitivity. The combined effect size amounted to $r=.31$, which 
Table 3

Meta-Analytic Associations Between AQS Security and Temperament $(k=27)$

\begin{tabular}{|c|c|c|c|c|c|c|}
\hline & $k$ & $N$ & $r$ & $95 \% \mathrm{CI}$ & $Q$ & $p$ \\
\hline Total set & 27 & $2,032^{\mathrm{a}}$ & $.29 * * *$ & $(.22 \sim .36)$ & 70.99 & $<.01$ \\
\hline Mother & 17 & 1,201 & $.35^{* * *}$ & $(.27 \sim .43)$ & 33.65 & $<.01$ \\
\hline Observer & 10 & 831 & $.16^{* * *}$ & $(.10 \sim .23)$ & 16.35 & .06 \\
\hline ANOVA contrast & & & & & 20.99 & $<.01$ \\
\hline \multicolumn{7}{|l|}{ AQS } \\
\hline AQS version & & & & & 0.11 & .74 \\
\hline 90 items & 7 & 707 & $.19^{* *}$ & $(.06 \sim .31)$ & $14.34^{*}$ & \\
\hline Other & 3 & 124 & $.19^{*}$ & $(.01 \sim .36)$ & 1.90 & \\
\hline Duration $^{\mathrm{b}}$ & & & & & 3.75 & .05 \\
\hline $180 \mathrm{~min}$ or less & 4 & 527 & $.11^{*}$ & $(.02 \sim .19)$ & 3.96 & \\
\hline More than $180 \mathrm{~min}$ & 4 & 215 & $.26^{* * *}$ & $(.13 \sim .39)$ & 7.07 & \\
\hline \multicolumn{7}{|l|}{ Interval $^{c}$} \\
\hline 1 month or less & 8 & 502 & $.17^{* * *}$ & $(.08 \sim .26)$ & 13.68 & \\
\hline More than 1 month & 2 & 329 & $.15^{* *}$ & $(.04 \sim .25)$ & 2.54 & \\
\hline \multicolumn{7}{|l|}{ Sample } \\
\hline \multicolumn{7}{|l|}{ Age $^{c}$} \\
\hline$<18$ months & 5 & 404 & $.16^{* *}$ & $(.06 \sim .26)$ & 5.46 & \\
\hline $19-30$ months & 2 & 299 & .11 & $(-.00 \sim .22)$ & 0.14 & \\
\hline$>30$ months & 3 & 128 & .31 & $(-.08 \sim .61)$ & $7.63^{*}$ & \\
\hline \multicolumn{7}{|l|}{ Clinical } \\
\hline No & 9 & 752 & $.15^{* * *}$ & $(.08 \sim .22)$ & 14.58 & \\
\hline Yes & 1 & 79 & $.30 * *$ & $(.08 \sim .49)$ & & \\
\hline Country $^{\mathrm{d}}$ & & & & & 3.52 & .06 \\
\hline United States & 6 & 522 & $.15^{* * *}$ & $(.06 \sim .23)$ & 5.29 & \\
\hline Canada & 3 & 180 & $.30 * * *$ & $(.16 \sim .43)$ & 5.06 & \\
\hline Europe & 1 & 129 & .04 & $(-.14 \sim .21)$ & & \\
\hline \multicolumn{7}{|l|}{ Publication } \\
\hline Medium & & & & & 0.00 & .98 \\
\hline Journal & 5 & 331 & .19 & $(-.03 \sim .39)$ & $12.54^{*}$ & \\
\hline Other & 5 & 500 & $.16^{* * *}$ & $(.08 \sim .25)$ & 3.80 & \\
\hline
\end{tabular}

Note. $\mathrm{AQS}=$ Attachment $Q$ Sort $\mathrm{CI}=$ confidence interval.

${ }^{a}$ The NICHD Early Child Care Research Network (1999) study was winsorized $(n=250)$.

${ }^{\mathrm{b}}$ Two studies were excluded because of missing information.

${ }^{\mathrm{c} C}$ Contrast not tested because of small subgroups.

${ }^{\mathrm{d}}$ Contrast United States versus Canada.

${ }^{*} p<.05 .{ }^{* *} p<.01 .{ }^{* * *} p<.001$.

indicated a substantial association between the AQS security and sensitivity in the expected direction (see Table 4). However, the observer AQS outcomes $(k=18, n=1,355)$ differed significantly from the selfreported AQS $(k=24, n=1,413)$. The self-reported AQS security was only modestly related to sensitivity $(r=.23)$, whereas the observer AQS correlated strongly $(r=.39)$. The difference between the effect sizes of these two subsets of study outcomes was significant, $Q(d f=1)=17.65, p<.01$. Again, the observer AQS showed the most (predictive) validity and was used to explore moderator influences.

Moderators of the association between the observer $A Q S$ and maternal sensitive responsiveness. The effect sizes of the studies on the association between the observer AQS and maternal sensitivity were heterogeneous, $Q(d f=17)=82.58, p<.01$. Significant moderators were country and publication medium. The AQS studies conducted in the United States showed only modest associations between security and sensitivity (combined $r=.20$ ) compared with studies conducted in other countries. Journal publications showed stronger effect sizes (combined $r=.48$ ) than other publications such as dissertations and conference presentations (combined $r=.28$ ). For duration of AQS observations, a trend in the expected direction was found but the contrast was not significant. Also, it did not make a significant difference for the 
Table 4

Meta-Analytic Associations Between AQS Security and Sensitivity $(k=42)$

\begin{tabular}{|c|c|c|c|c|c|c|}
\hline & $k$ & $N$ & $r$ & $95 \% \mathrm{CI}$ & $Q$ & $p$ \\
\hline Total set & 42 & $2,768^{\mathrm{a}}$ & $.31^{* * *}$ & $(.24 \sim .37)$ & 132.87 & $<.01$ \\
\hline Mother & 24 & 1,413 & $.23^{* * *}$ & $(.18 \sim .28)$ & 32.64 & .09 \\
\hline Observer & 18 & 1,355 & $.39^{* * *}$ & $(.28 \sim .50)$ & 82.58 & $<.01$ \\
\hline ANOVA contrast & & & & & 17.65 & $<.01$ \\
\hline \multicolumn{7}{|l|}{ AQS (observed) } \\
\hline \multicolumn{7}{|l|}{ AQS version ${ }^{\mathrm{b}}$} \\
\hline 90 items & 16 & 1,235 & $.38^{* * *}$ & $(.26 \sim .48)$ & $64.89^{* * *}$ & \\
\hline Other & 2 & 120 & .52 & $(-.11 \sim .85)$ & $7.78^{* *}$ & \\
\hline Duration $^{\mathrm{b}}$ & & & & & 2.06 & .15 \\
\hline $180 \mathrm{~min}$ or less & 8 & 744 & $.35^{* * *}$ & $(.18 \sim .50)$ & $33.99 * * *$ & \\
\hline More than $180 \mathrm{~min}$ & 8 & 482 & $.45^{* * *}$ & $(.27 \sim .60)$ & $30.89^{* * *}$ & \\
\hline \multicolumn{7}{|l|}{ Interval $^{c}$} \\
\hline 1 month or less & 15 & 1,074 & $.39 * * *$ & $(.26 \sim .50)$ & $63.41^{* * *}$ & \\
\hline More than 1 month & 3 & 271 & $.42^{*}$ & $(.01 \sim .71)$ & $18.46^{* * *}$ & \\
\hline \multicolumn{7}{|l|}{ Sample } \\
\hline Age & & & & & 4.71 & .10 \\
\hline$<18$ months & 9 & 764 & $.42^{* * *}$ & $(.25 \sim .57)$ & $52.20 * * *$ & \\
\hline $19-30$ months & 5 & 435 & $.44^{* *}$ & $(.18 \sim .64)$ & $22.28 * * *$ & \\
\hline$>30$ months & 4 & 156 & $.25^{* *}$ & $(.10 \sim .40)$ & 3.39 & \\
\hline Clinical & & & & & 1.35 & .25 \\
\hline Yes & 6 & 411 & $.35^{* *}$ & $(.10 \sim .56)$ & $28.75^{* * *}$ & \\
\hline No & 12 & 944 & $.42^{* * *}$ & $(.28 \sim .54)$ & $52.49^{* * *}$ & \\
\hline Country $^{\mathrm{d}}$ & & & & & 56.69 & $<.001$ \\
\hline United States & 8 & 717 & $.20 * * *$ & $(.13 \sim .27)$ & 7.06 & \\
\hline Canada & 6 & 333 & $.53^{* * *}$ & $(.36 \sim .67)$ & $15.49^{* *}$ & \\
\hline Europe & 1 & 129 & $.48^{* * *}$ & $(.33 \sim .60)$ & & \\
\hline Other & 3 & 176 & $.57^{* * *}$ & $(.46 \sim .67)$ & 3.34 & \\
\hline \multicolumn{7}{|l|}{ Publication } \\
\hline Medium & & & & & 16.81 & $<.001$ \\
\hline Journal & 10 & 699 & $.48^{* * *}$ & $(.32 \sim .61)$ & $47.46^{* * *}$ & \\
\hline Other & 8 & 656 & $.28 * * *$ & $(.15 \sim .41)$ & $18.31^{*}$ & \\
\hline
\end{tabular}

Note. $\mathrm{AQS}=$ Attachment $Q$ Sort; $\mathrm{CI}=$ confidence interval.

${ }^{a}$ The NICHD Early Child Care Research Network (1999) study was winsorized $(n=250)$.

${ }^{\mathrm{b}}$ Two studies were excluded because of missing information.

${ }^{c}$ Contrast not tested because of small subgroups.

${ }^{\mathrm{d} C}$ Contrast United States versus Canada.

${ }^{*} p<.05 .{ }^{* *} p<.01 .{ }^{* * *} p<.001$.

outcomes whether the samples were clinical, or whether the sensitivity assessment was conducted before or concurrently with the AQS (within a 1month period).

\section{Association Between the AQS and Socioemotional Development: Predictive Validity}

Total set of AQS studies. In 33 samples $(n=2,035)$ AQS security was related to facets of socioemotional development such as problem behaviors and social competence in peer relations (see Table 5). The combined effect size was $r=.22$, which indicated a modest association between AQS security and social competence. Although this set of studies was homogeneous in the statistical sense, it consisted of divergent types of measures. One large subset of studies focused on the child's social competence in peer relations, and this subset showed a similar combined effect size of $r=.18(k=15, n=878)$. In both sets of studies, it did not make a difference whether the observer or the self-reported AQS had been used.

Moderators of the association between the observer $A Q S$ and socioemotional development. In the set of studies with the observer AQS we did not find significant moderators (see Table 5). 
Table 5

Meta-Analytic Associations Between AQS Security and Socioemotional Development $(k=33)$

\begin{tabular}{|c|c|c|c|c|c|c|}
\hline & $k$ & $N$ & $r$ & $95 \% \mathrm{CI}$ & $Q$ & $p$ \\
\hline Total set & 33 & $2,035^{\mathrm{a}}$ & $.22^{* * *}$ & $(.18 \sim .26)$ & 42.74 & \\
\hline Mother & 24 & 1,316 & $.22 * * *$ & $(.16 \sim .27)$ & 34.39 & \\
\hline Observer & 9 & 719 & $.23 * * *$ & $(.15 \sim .30)$ & 8.30 & \\
\hline ANOVA contrast & & & & & 0.05 & .83 \\
\hline \multicolumn{7}{|l|}{ Social competence peers } \\
\hline Total set & 15 & $878^{\mathrm{a}}$ & $.18^{* * *}$ & $(.11 \sim .24)$ & 17.00 & \\
\hline Mother & 11 & 616 & $.15^{* * *}$ & $(.07 \sim .23)$ & 8.27 & \\
\hline Observer & 4 & 262 & $.24^{* * *}$ & $(.12 \sim .35)$ & 7.28 & \\
\hline ANOVA contrast & & & & & 1.46 & .23 \\
\hline \multicolumn{7}{|l|}{ AQS (observed) } \\
\hline Duration & & & & & 1.63 & .20 \\
\hline $180 \mathrm{~min}$ or less & 5 & 431 & $.26^{* * *}$ & $(.17 \sim .35)$ & 3.57 & \\
\hline More than $180 \mathrm{~min}$ & 4 & 288 & $.17^{* *}$ & $(.05 \sim .28)$ & 3.10 & \\
\hline Interval & & & & & 0.12 & .72 \\
\hline 1 month or less & 6 & 485 & $.22 * * *$ & $(.13 \sim .30)$ & 5.16 & \\
\hline More than 1 month & 3 & 234 & $.24^{* * *}$ & $(.12 \sim .36)$ & 3.02 & \\
\hline \multicolumn{7}{|l|}{ Sample } \\
\hline Age & & & & & 0.00 & .97 \\
\hline $19-30$ months & 3 & 333 & .23 & $(-.06 \sim .47)$ & $6.55^{*}$ & \\
\hline$>30$ months & 6 & 386 & $.23^{* * *}$ & $(.13 \sim .32)$ & 1.75 & \\
\hline \multicolumn{7}{|l|}{ Clinical } \\
\hline \multicolumn{7}{|l|}{ Yes } \\
\hline No & 9 & 719 & $.23 * * *$ & $(.15 \sim .30)$ & 8.30 & \\
\hline \multicolumn{7}{|l|}{ Country $^{b}$} \\
\hline North-America & 5 & 557 & $.24 * * *$ & $(.16 \sim .32)$ & 1.15 & \\
\hline Canada & 1 & 29 & .09 & $(-.29 \sim .44)$ & & \\
\hline Europe & 2 & 83 & .23 & $(-.44 \sim .74)$ & $6.29^{*}$ & \\
\hline Other & 1 & 50 & .23 & $(-.05 \sim .48)$ & & \\
\hline \multicolumn{7}{|l|}{ Publication } \\
\hline Medium & & & & & 0.48 & .49 \\
\hline Journal & 5 & 308 & $.20 * * *$ & $(.09 \sim .30)$ & 4.80 & \\
\hline Other & 4 & 411 & $.25^{* * *}$ & $(.15 \sim .34)$ & 3.02 & \\
\hline
\end{tabular}

Note. AQS = Attachment $Q$ Sort; $\mathrm{CI}=$ confidence interval.

${ }^{a}$ The NICHD Early Child Care Research Network (1999) study was winsorized $(n=250)$.

${ }^{\mathrm{b}}$ Two studies were excluded because of missing information.

${ }^{* *} p<.01 .{ }^{* * *} p<.001$.

\section{Multivariate Moderator Analysis}

Multiple regression was used to examine whether the considerable moderator effect of country (United States vs. other countries) on the relation between AQS security on the one hand and SSP security and maternal sensitive responsiveness on the other might be explained by other moderators associated with this country effect. Because age of the children in the U.S. samples was significantly higher than in the other samples and because of the important moderator effect of duration of AQS observation, we conducted multivariate hierarchical regressions with effect sizes as the dependent variable (correlations were transformed to Fisher $Z$ with the inverse variance as weights), and age and duration of AQS observation as predictors in the first step, and country (United States vs. other countries) in the second step. For the effect sizes of observer AQS and SSP $(k=17)$, we still found a significant contribution of country (beta weight $=.73, p<.01$ ), even after controlling for age and duration. For the effect sizes of observer AQS and sensitivity $(k=18)$, we also found a significant unique contribution of country (beta weight $=.78$, $p<.01$ ), again after controlling for age and duration. The multivariate regressions underlined the impor- 
tant moderator role of country, independent of other significant moderators.

\section{Stability}

In four studies (Clark \& Symons, 2000; Howes \& Hamilton, 1992b; Symons, Clark, Isaksen, \& Marshall, 1998; Vereijken, Hanta, \& Van Lieshout, 1997) the combined stability correlation for the observer AQS was $r=.28(n=162)$ in a homogeneous set of stability studies $(95 \% \mathrm{CI}=.12 \sim .42)$. This stability estimate is modest.

\section{Fathers and Professional Caregivers: Validity of the AQS}

The number of studies on AQS security in fathers and in professional caregivers was disappointingly small. The combination of the two studies on the association between AQS security and the SSP in fathers (Caldera, 1990; Youngblade, Park, \& Belsky, 1993) did not result in a significant effect size. Also, no significant meta-analytic results were found for the four studies on AQS security and paternal sensitivity, or for the four studies on AQS security and socioemotional development. All but one study included in these meta-analyses were based on the self-report AQS. From a meta-analytic perspective the validity of the AQS for fathers still has to be documented. Incidentally, the same holds true for the SSP with fathers (Van IJzendoorn \& De Wolff, 1997).

For professional caregivers, significant combined effect sizes were found: for SSP security ( $k=2$; one observer AQS, one self-report AQS), combined $r=.23$; for socioemotional development $(k=9$; one study with self-report AQS), combined $r=.19$; and for sensitivity ( $k=4$; all observer AQS), combined $r=.09$, but the number of studies was small. Whether child-caregiver relationships may really be interpreted as attachments still is an issue of considerable debate (Howes, 1999). More work in this area should be conducted before the validity of the AQS for this group of caregivers can be considered to be established.

\section{Discussion}

Is the AQS a valid measure of attachment security? We conducted a series of meta-analyses on the extant AQS studies to test the convergent, predictive, and discriminant validity of this alternative attachment measure. The observer AQS, but not the self-reported AQS, appeared to show sufficient validity to be considered an adequate assessment of attachment. In fact, after more than 130 AQS studies on thousands of children it is safe to conclude that this attachment measure belongs to the small set of gold standards in our field, in the same league with the SSP and the Adult Attachment Interview (AAI).

In 28 normal samples $(n=2,516)$ we found an average observer AQS security score of .32. The observer AQS showed substantial convergent validity with the SSP, certainly when the duration of AQS observations lasted more than $3 \mathrm{hr}$ per child to guarantee a broad coverage of attachment behavior in the natural setting. With more than $3 \mathrm{hr}$ of observations, the combined effect size for the association between AQS security and SSP security amounted to $r=.42$. Of course, the association is far from perfect, and we may conclude that both measures assess overlapping but different dimensions of the same security construct. The SSP emphasizes the dynamics of the attachment behavioral system in stressful situations and focuses on the child's expectations of parental protection in times of stress and anxiety, whereas the AQS emphasizes the interplay between the attachment and exploratory systems in the natural setting and addresses the child's expectations of parental guidance in more regular circumstances (Solomon \& George, 1999).

The observer AQS also showed an impressive predictive validity. In particular, the observer AQS correlated strongly with sensitive responsiveness. The association between attachment security and parental sensitivity is widely considered to be one of the cornerstones and key assumptions of attachment theory (Main, 1999). In fact, the average correlation between the SSP and sensitive responsiveness as assessed with the Ainsworth rating scales $(r=.24$; De Wolff \& Van IJzendoorn, 1997) is considerably smaller than the combined effect size we found in our meta-analysis of the observer AQS studies. Longer duration of observations (more than $3 \mathrm{hr}$ ) resulted in a large effect size $(r=.45)$.

The association between the observer AQS and maternal sensitivity may, however, be inflated. In several studies both attachment security and sensitivity were measured in the same situation, and some of the strongest associations between the observer AQS and sensitivity were found in studies in which AQS security scores and sensitivity scores were derived from the same observational situations and settings, albeit by different observers. For example, in the Symons et al. (1995) study the correlation between security and sensitivity in the same situation (with different observers) amounted to .59, whereas this association was $r=.20$ when the AQS security score was correlated with maternal respon- 
sive guidance in an independent laboratory setting. Other researchers, however, found much less discrepancy between the correlation of AQS scores and maternal sensitivity observed at home and -1 week later - in a laboratory setting (Van Bakel \& RiksenWalraven, in press), thus contradicting the inflation argument.

The evidence for a crucial role of attachment security in the child's socioemotional development was not confirmed in this meta-analysis, although a robust combined effect of moderate size was documented (combined $r=.22$ across 33 studies). This effect size is comparable to the outcome of the meta-analysis by Schneider, Atkinson, and Tardif (2001), who worked with a broader set of attachment measures. It is still subject to considerable debate whether attachment security should predict social competence in general or only those facets that are related to intimate relationships (Sroufe, 1988). It should also be noted that AQS attachment security is more strongly related to socioemotional competence than is SSP attachment security (combined $r=.12$ across 26 studies in the Schneider et al., 2001, meta-analysis).

In comparing AQS and SSP it should be noted that the number of studies on the determinants and sequelae of AQS security is still smaller than that of comparable SSP studies. For example, only a few studies assessed parental sensitivity some months before the attachment assessment, and intervention studies on parental sensitivity with the AQS as outcome measure, documenting the causal connection, are scarce. Furthermore, it is still largely unknown whether the AQS shows the expected lawful (dis)continuity of attachment across time that has been discovered with the SSP, that is, predictable changes of attachment depending on major changes in childrearing circumstances (Sroufe, 1988). For attachment security in early childhood some stability over time may be expected, although Bowlby (1973) emphasized the environmental lability of attachment during the first 5 years of life. In our meta-analysis we found a stability estimate of modest size, $r=.28$ (but see Fraley, 2002). It should be noted that this stability figure should not be confused with testretest reliability, which may be computed from studies with repeated application of the AQS to the same children, preferably within short intervals (Lamb et al., 1985; Vaughn et al., 1979). In studies with longer intervals between repeated AQS assessments, data on changes in parental sensitivity or life circumstances are needed to evaluate properly testretest reliability.

The observer AQS has also been tested less thoroughly in cross-cultural studies compared with SSP studies (Van IJzendoorn \& Sagi, 1999), although there is increasing evidence for its cross-cultural validity (Waters et al., 1995). An important advantage of the AQS for further research into the security concept is the possibility of creating culture-specific criterion sorts for security. That is, local experts have been asked to provide the sort for the ideal-type secure child in their cultural context (Posada, Gao, et al., 1995; Vereijken, Riksen-Walraven, \& Van Lieshout, 1997). Preliminary findings with this approach appear to establish the cross-cultural validity of the AQS in various Western as well as non-Western societies (Posada, Gao, et al., 1995; Vereijken, Riksen-Walraven, \& Van Lieshout, 1997). Local experts and parents appear to sort the ideal-secure child in similar ways across various and diverging cultures such as Japan, Colombia, and the United States (Posada, Gao, et al., 1995; Vereijken, RiksenWalraven, \& Van Lieshout, 1997). This is a crucial test for the assumption that across cultures attachment security is indeed perceived in a similar way, by native experts as well as parents. The outcome stresses the validity of applying the AQS and the original ideal-type criterion sort in a similar way cross-culturally.

In the current meta-analysis we found that the AQS seemed to work even better in Canada and in the European countries than in the United States, from which the AQS originated. It should be noted that in all studies the original ideal-type security sort had been used (Waters \& Deane, 1985). It is puzzling that AQS studies from the United States show less strong validity results, which are not related to the differences in age of the samples from the United States versus the other samples or to the duration of AQS observations. In particular, the Canadian studies show strong results, but it is unclear what systematic differences in approach or participants are responsible for this difference. Whatever its source, our meta-analytic findings certainly do not suggest that the AQS cannot be applied validly in or outside its country of origin.

Different versions of the AQS have been used in different ways. Since the first 100-item version of the AQS was proposed (Waters \& Deane, 1985), several adjustments in the number of items and phrasing have been made. The studies that have been conducted so far confirm the impression that there are no clear differences in effect size between the $Q$-sort versions. The AQS has shown to be robust against minor adaptations.

Data-collection procedures may also affect the validity of the AQS. To describe a child with the AQS, it is necessary to collect a representative sam- 
ple of child behaviors. Trained observers can achieve this by observing the child over different occasions and for an extended time. Furthermore, to improve reliability of the AQS description, different observers can be asked to describe the same child. The descriptions can later be turned into one composite AQS description, which is more reliable than the separate descriptions (Block, 1961). Waters and Deane (1985) proposed to collect a representative sample of child behavior by visiting the families three times for $3 \mathrm{hr}$. First, one observer visits alone. Then, the same observer visits again accompanied by a second observer. Finally, the second visitor makes the third visit alone. Obviously, although Waters and Deane's scheme for data collection is thorough, it is also time consuming and therefore sometimes impractical. In later studies, data-collection procedures were simplified by reducing the number and duration of the visits and the number of observers.

However, if the data-collection procedure is simplified too much the sample of child behaviors may be too limited, and reliable and valid data may be harder to get. Our meta-analytic findings showed that more valid AQS data were collected in studies with more than $3 \mathrm{hr}$ of observation. This is not to say that valid data cannot be obtained in home visits of shorter durations. Studies of Moran, Pederson, Pettit, and Krupka (1992), Vereijken, Riksen-Walraven, and Kondo-Ikemura (1997), and Van Bakel and RiksenWalraven (2002, in press) showed AQS scores based on 90 and $120 \mathrm{~min}$ of observation to be significantly related to parental sensitivity, SSP-derived security, or both. In these studies, however, parts of the home observations were more or less structured to enhance the chance to observe certain child behaviors that are only rarely observed in some children in the natural setting. Although such structuring inevitably introduces some artificiality, which is exactly what the designers of the AQS intended to avoid, it has the advantage of limiting the time needed to observe children's use of the parent as a secure base at home. If structuring involves inducing mild stress it may also ensure that attachment behavior is triggered in all children and that their behavioral differences can be observed under similar conditions. More studies with variation in duration of observations or (possibly some stress-inducing) structuring of the setting are needed to provide meta-analytic evidence to choose an optimal balance between duration and structure.

Support for the validity of the self-reported (or mother) AQS was less convincing. The association between the self-reported AQS and the SSP was disappointingly weak (combined effect size $r=.14$ ), and the instrument showed a strong association with temperamental reactivity (combined $r=.35$ ). The convergent and discriminant validity of the self-reported AQS does not yet warrant its use as a measure of attachment security. The modest predictive validity of the mother AQS with maternal sensitivity and later social competence does not compensate for the lack of convergent and discriminant validity, and it is still unclear what is measured with this application of the AQS. Mothers of insecure children may lack the observational skills necessary for a balanced registration of secure-base behaviors in their children. In fact, the self-reported AQS might suffer from the paradox of any self-diagnosis because the observer is an active part of the observed dyadic system. Vereijken and Kondo-Ikemura (2004) showed that when mothers were more sensitive, their $Q$-sort descriptions were more similar to the descriptions of the observers. Stevenson-Hinde and Shouldice (1990) found that mothers of secure children consistently assessed their children's attachment security lower than did observers, whereas mothers of insecure children consistently assessed their children's attachment security higher than did observers. Mothers of secure children may be less defensive in their perception of (negative) attachment behavior (Main, 1990; Zeijlmans van Emmichhoven, Van IJzendoorn, de Ruiter, \& Brosschot, 2003).

In conclusion, the assessment of attachment security remains a choice between laborious but unobtrusive and repeatable AQS observations in the natural setting, and a brief but stressful and artificial laboratory procedure (the SSP). In most cases the characteristics of the research setting dictate which instrument to use. If different forms of insecurity should be discriminated, the SSP classifications are required. The same is true for situations in which the assessment of disorganized attachment (Main \& Solomon, 1990) is critical. Although disorganized attachment behaviors appear to lead to extremely low AQS scores, validation of the AQS as an index of attachment disorganization still has to begin. Recent research suggests that analyzing the AQS at the level of individual items is a fruitful approach for discriminating disorganized from nondisorganized children (Van Bakel \& Riksen-Walraven, in press).

Although the SSP therefore cannot be replaced by the AQS, the AQS has some unique advantages. In new (cross-cultural or clinical) populations the exploratory use of the AQS may be especially rewarding because the researcher may get to know the specific secure-base behavior of the children in more detail. The AQS also allows for the measurement of other constructs besides attachment, such as dependence and sociability (Vaughn \& Waters, 1990). 
Furthermore, if continuous measures are needed across a larger age range (e.g., in short-term longitudinal studies), the observer AQS may prove more useful than the SSP. The same may be true for intervention studies in which repeated attachment assessments are required (Bakermans-Kranenburg et al., 2003). It should be noted that with increasing age the observer AQS seems to show less validity (convergent and predictive validity), which may emphasize the need for age-specific criterion sorts that might differ for infants, toddlers, and preschoolers (Solomon \& George, 1999). In sum, the observer AQS cannot replace the SSP, but it is in a good position to release attachment theory from its exclusive bond to a single measurement procedure. This way, the AQS may help separate the concept of attachment in young children from the way it is measured.

\section{References}

*Aber, J. L., \& Baker, A. J. L. (1990). Security of attachment in toddlerhood: Modifying assessment procedures for joint clinical and research purposes. In $M$. $T$. Greenberg, D. Cicchetti, \& E. M. Cummings (Eds.), Attachment in the preschool years: Theory, research, and intervention (pp. 427-460). Chicago: University of Chicago Press.

Achenbach, T. M. (1985). Assessment and taxonomy of child and adolescent psychopathology. London: Sage.

Ainsworth, M. D. S., Bell, S. M., \& Stayton, D. J. (1974). Infant-mother attachment and development: "Socialization" as a product of reciprocal responsiveness to signals. In M. P. Richards (Ed.), The integration of a child into a social world (pp. 99-135). London: Cambridge University Press.

Ainsworth, M. D. S., Blehar, M. C., Waters, E., \& Wall, S. (1978). Patterns of attachment. Hillsdale, NJ: Erlbaum.

Ainsworth, M. D. S., \& Wittig, B. A. (1969). Attachment and exploratory behavior of one-year-olds in a Strange Situation. In B. M. Foss (Ed.), Determinants of infant behavior (Vol. 4, pp. 113-136). London: Methuen.

*Atkinson, L., Vaughn, B. E., Chisholm, V. E., Blackwell, J., \& Tam, F. (1996). Attachment security and functional level: Toddlers with Down syndrome. Unpublished manuscript.

Atkinson, L., Chisholm, V. C., Scott, B., Goldberg, S., Vaughn, B. E., Blackwell, J., et al. (1999). Maternal sensitivity, child functional level, and attachment in Down syndrome. Monographs of the Society for Research in Child Development, 64(Serial No. 258), 45-66.

*Bailey, H. N., Waters, C. A., Pederson, D. R., \& Moran, G. (1999). Ainsworth revisited: An empirical analysis of interactive behavior in the home. Attachment and Human Development, 1, 191-216.

*Bakermans-Kranenburg, M. J., van IJzendoorn, M. H., Bokhorst, C. L., \& Schuengel, C. (in press). The impor- tance of shared environment in infant-father attachment: A behavioral genetic study of the Attachment Q-Sort. Journal of Family Psychology.

Bakermans-Kranenburg, M. J., van IJzendoorn, M. H., \& Juffer, F. (2003). Less is more: Meta-analyses of sensitivity and attachment interventions in early childhood. Psychological Bulletin, 129, 195-215.

*Belsky, J., \& Rovine, M. (1990). Q-sort security and first year nonmaternal care. In K. McCartney (Ed.), New Directions in Child Development, 49, 7-22

*Blicharsky, T., \& Verissimo, M. (1992, September). Behavioral characteristics associated with maternal representations of attachment for toddlers. Paper presented at the fifth European Conference on Developmental Psychology, Seville, Spain.

Block, J. (1961). The Q-sort method in personality assessment and psychiatric research. Palo Alto, CA: Consulting Psychologists Press.

Bokhorst, C. L., Bakermans-Kranenburg, M. J., Fearon, P., van IJzendoorn, M. H., Fonagy, P., \& Schuengel, C. (2003). The importance of shared environment in mother-infant attachment: A behavioral genetic study. Child Development, 74, 1769-1782

Borenstein, M., \& Rothstein, D. (1999). Comprehensive MetaAnalysis. A computer program for research synthesis. Englewood, NJ: Biostat.

Borenstein, M., Rothstein, D., \& Cohen, J. (2000). Comprehensive Meta-Analysis. A computer program for research synthesis. Englewood, NJ: Biostat.

*Bosso, O. R., Corter, C. M., \& Abramovitch, R. (1996). Attachment security in three-year-old first born children: Relations to Strange Situation classifications and to behavior toward a younger sibling. Unpublished manuscript, University of Toronto, Canada.

*Bost, K. K., Vaughn, B. E., Washington, W. N., Cielinski, K. L., \& Bradbard, M. R. (1998). Social competence, social support, and attachment: Demarcation of construct domains, measurement, and paths of influence for preschool children attending head start. Child Development, 69, 192-218.

Bowlby, J. (1969). Attachment and loss. Vol. 1: Attachment. New York: Basic Books.

Bowlby, J. (1973). Attachment and loss. Vol. 2: Separation, anxiety and anger. London: Hogarth, Penguin.

Bretherton, I. (1985). Theory and assessment-Introduction. Monographs of the Society for Research in Child Development, 50(Serial No. 209), 39-40.

*Bretherton, I., Biringen, Z., Ridgeway, D., Maslin, C., \& Sherman, M. (1989). Attachment: The parental perspective. Infant Mental Health Journal, 10, $203-$ 221.

*Bretherton, I., Ridgeway, D., \& Cassidy, J. (1990). Assessing internal working models of the attachment relationship: An attachment story completion task for 3-year-olds. In M. T. Greenberg, D. Cicchetti, \& E. M. Cummings (Eds.), Attachment in the preschool years: Theory, research, and intervention (pp. 284-297). Chicago: University of Chicago Press. 
Bronfenbrenner, U. (1979). The ecology of human development. Cambridge, MA: Harvard University Press.

*Busch-Rossnagel, N. A., Fracasso, M. P., \& Vargas, M. (1994). Reliability and validity of a Q-sort measure of attachment security in Hispanic infants. Hispanic Journal of Behavioral Sciences, 16, 240-254.

*Caldera, Y. M. (1990). Infant daycare and maternal characteristics as predictors of attachment and compliance (daycare). Unpublished doctoral dissertation, University of Kansas, Kansas.

*Caldera, Y. M. (1992, May). Paternal involvement and infant-father attachment. Paper presented at the International Conference on Infant Studies, Miami, FL.

*Cassibba, R., van IJzendoorn, M. H., \& D'Odorico, L. (2000). Attachment and play in child care centres: Reliability and validity of the Attachment Q-sort for mothers and professional caregivers in Italy. International Journal of Behavioral Development, 24, 241-255.

Cassidy, J., \& Shaver, P. R. (1999). Handbook of attachment. Theory, research, and clinical applications. New York: Guilford Press.

*Chisholm, K., Carter, M. C., Ames, E. W., \& Morison, S. J. (1995). Attachment security and indiscriminately friendly behavior in children adopted from Romanian orphanages. Development and Psychopathology, 7, 283-294.

*Cicchetti, D., Toth, S. L., \& Rogosch, F. A. (1999). The efficacy of toddler-parent psychotherapy to increase attachment security in offspring of depressed mothers. Attachment and Human Development, 1, 34-66.

*Clark, S. E., \& Symons, D. K. (2000). A longitudinal study of Q-sort attachment security and self-processes at age 5 . Infant and Child Development, 9, 91-104.

*Clements, M., \& Barnett, D. (2002). Parenting and attachment among toddlers with congenital anomalies: Examining the strange situation and attachment Q-sort. Infant Mental Health Journal, 23, 625-642.

Cohn, D. A., Patterson, C. J., \& Christopoulos, C. (1991). The family and children's peer relations. Journal of Social and Personal Relationships, 8, 315-346.

*Coutu, S., Provost, N., \& Pelletier, D. (1996). Motherchild relationship and quality of interactions among preschool siblings. Canadian Journal of Behavioral Science, $28,1-11$.

*Cutler, K. M.-Z. (1996). Parent-child attachment and communication styles: Relations with preschoolers' peer communication styles. Dissertation Abstracts International: A. The Humanities and Social Sciences, 57, 571.

*Das Eiden, R., Teti, D. M., \& Corns, K. M. (1995). Maternal working models of attachment, marital adjustment, and the parent-child relationship. Child Development, 66, 1504-1518.

* Del Carmen, R., Huffman, L. C., Pedersen, F., \& Bryan, Y. E. (2000). Mothers' and fathers' perceptions of three year olds' attachment. Journal of Developmental and Behavioral Pediatrics, 21, 97-106.

* DeMulder, E. K., Denham, S., Schmidt, M., \& Mitchell, J. (2000). Q-sort assessment of attachment security during the preschool years: Links from home to school. Developmental Psychology, 36, 274-282.

*Denham, S., Blair, K., Schmidt, M., \& DeMulder, E. (2002). Compromised emotional competence: Seeds of violence sown early. American Journal of Orthopsychiatry, 72, $70-82$.

*Denham, S., Mason, T., Caverly, S., Schmidt, M., Hackney, R., Caswell, C., et al. (2001). Preschoolers at play: Cosocialisers of emotional and social competence. International Journal of Behavioral Development, 25, 290-301.

* De Roos, S. A. (1995). Peer competence and its antecedents during the first five years of life: A longitudinal study. Nijmegen, Netherlands: Universiteitsdrukkerij.

De Wolff, M. S., \& van IJzendoorn, M. H. (1997). Sensitivity and attachment: A meta-analysis on parental antecedents of infant attachment. Child Development, 68, 571-591.

* Diener, M. L., Nievar, M. A., \& Wright, C. (2003). Attachment security among mothers and their young children living in poverty: Associations with maternal, child, and contextual characteristics. Merrill-Palmer Quarterly, 49, 154-182.

* Digiaro, D. A. (1991). Maternal attachment history variables as they relate to mother's separation concerns, child's attachment patterns, and child's preschool behavior. Abstract obtained from ProQuest File, Abstract No. 9035008.

Elicker, J., Englund, M., \& Sroufe, A. (1992). Predicting peer competence and peer relationships in childhood from early parent-child relationships. In D. S. Parke \& G. W. Ladd (Eds.), Family-peer relationships: Modes of linkage (pp. 77-106). Hillsdale, NJ: Erlbaum.

*Elicker, J., Forner-Wood, C., \& Noppe, I. C. (1999). The context of infant attachment in family child care. Journal of Applied Developmental Psychology, 20, 319-336.

Fox, N. A., Kimmerly, N. L., \& Schafer, W. D. (1991). Attachment to mother/attachment to father: A metaanalysis. Child Development, 62, 210-225.

Fraley, R. C. (2002). Attachment stability from infancy to adulthood: Meta-analysis and dynamic modeling of developmental mechanisms. Personality and Social Psychology Review, 6, 123-151.

*Frosch, C. A., Mangelsdorf, S. C., \& McHale, J. L. (2000). Marital behavior and the security of preschooler - parent attachment relationships. Journal of Family Psychology, 14, $144-161$.

Goldsmith, H. H., \& Alansky, J. A. (1987). Maternal and infant temperamental predictors of attachment: A metaanalytic review. Journal of Consulting and Clinical Psychology, 55, 805-816.

*Hadadian, A., \& Merbler, J. (1996). Mother's stress: Implications for attachment relationships. Early Child Development and Care, 12, 59-66.

Hampel, F. R., Ronchetti, E. M., Rousseeuw, P. J., \& Stahel, W. A. (1986). Robust statistics: The approach based on influence functions. New York: Wiley.

Hedges, L. V., \& Olkin, I. (1985). Statistical methods for metaanalysis. San Diego, CA: Academic Press.

Howes, C. (1999). Attachment relationships in the context of multiple caregivers. In J. Cassidy \& P. Shaver (Eds.), 
Handbook of attachment theory and research (pp. 671-687). New York: Guilford Press.

*Howes, C., \& Hamilton, C. E. (1992a). Children's relationships with caregivers: Mothers and child care teachers. Child Development, 63, 859-866.

*Howes, C., \& Hamilton, C. E. (1992b). Children's relationships with child care teachers: Stability and concordance with maternal attachments. Child Development, $63,879-892$.

*Howes, C., Hamilton, C. E., \& Matheson, C. C. (1994). Children's relationships with peers: Differential associations with aspects of the teacher-child relationship. Child Development, 65, 253-263.

*Howes, C., Matheson, C. C., \& Hamilton, C. E. (1994). Maternal, teacher, and child care history: Correlates of children's relationships with peers. Child Development, $65,264-273$.

*Howes, C., Phillips, D. A., \& Whitebook, M. (1992). Thresholds of quality: Implications for the social development of children in center-based child care. Child Development, 63, 449-460.

*Howes, C., \& Ritchie, S. (1998). Changes in child - teacher relationships in a therapeutic preschool program. Early Child Education and Development, 9, 411-422.

*Howes, C., \& Ritchie, S. (1999). Attachment organizations in children with difficult life circumstances. Development and Psychopathology, 11, 251-268.

*Howes, C., \& Smith, E. W. (1995). Children and their child care caregivers: Profiles of relationships. Social Development, 4, 44-61.

*Hron-Stewart, K. (1989). Mastery, problem-solving and attachment in the second and third years of life. Unpublished doctoral dissertation, University of Illinois at Chicago.

*Jacobson, S. W., \& Frye, K. F. (1991). Effect of maternal social support on attachment: Experimental evidence. Child Development, 62, 572-582.

*Jarvis, P. A., \& Creasey, G. L. (1991). Parental stress, coping, and attachment in families with an 18-monthold infant. Infant Behavior and Development, 14, 383-395.

*Kazui, M., Endo, T., Tanaka, A., Sakagami, H., \& Suganuma, M. (2000). Intergenerational transmission of attachment Japanese mother - child dyads. Japanese Journal of Educational Psychology, 48, 323-332.

*Kerns, K. A. (2000). Types of preschool friendships. Personal Relationships, 7, 311-324.

*Kerns, K. A., \& Barth, J. M. (1995). Attachment and play: Convergence across components of parent-child relationships and their relations to peer competence. Journal of Social and Personal Relationships, 12, 243-260.

*Kerns, K. A., Cole, A., \& Andrews, P. B. (1998). Attachment security, parent peer management practices, and peer relationships in preschoolers. Merrill-Palmer Quarterly, 44, 504-522.

*Kochanska, G. (1995). Children's temperament, mothers discipline, and security of attachment: Multiple pathways to emerging internalization. Child Development, 66, 597-615.
*Kondo-Ikemura, K., \& Sogon, S. (1996). Secure base behavior and Strange Situation classifications in Japan. Unpublished manuscript, Osaka University.

Kondo-Ikemura, K., \& Waters, E. (1995). Maternal behavior and infant security in old world monkeys: Conceptual issues and a methodological bridge between human and non-human primate research. In E. Waters, B. E. Vaughn, G. Posada, \& K. Kondo-Ikemura (Eds.), Caregiving, cultural, and cognitive perspectives on secure-base behavior and working models: New growing points of attachment theory and research. Monographs of the Society for Research in Child Development, 60(2-3, Serial No. 244), $97-110$.

*Krupka, A. (1995). The quality of mother-infant interactions in families at risk for maladaptive parenting. Unpublished doctoral dissertation, The University of Western Ontario.

*Laible, D. J., \& Thompson, R. A. (1998). Attachment and emotional understanding in preschool children. Developmental Psychology, 34, 1038-1045.

*Laible, D. J., \& Thompson, R. A. (2000). Mother-child discourse, attachment security, shared positive affect, and early conscience development. Child Development, 71, 1424-1440.

Lamb, M. E., \& Nash, A. (1989). Infant-mother attachment, sociability and peer competence. In T. J. Berndt \& G. W. Ladd (Eds.), Peer relationships in child development (pp. 219-246). New York: Wiley.

Lamb, M. E., Thompson, R. A., Gardner, W., \& Charnov, E. L. (1985). Infant-mother attachment: The origins and developmental significance of individual differences in Strange Situation behavior. Hillsdale, NJ: Erlbaum.

* Lay, K. L., Waters, E., Posada, G., \& Ridgeway, D. (1995). Attachment security, affect regulation, and defensive responses to mood induction. In E. Waters, B. E. Vaughn, G. Posada, \& K. Kondo-Ikemura (Eds.), Caregiving, cultural, and cognitive perspectives on secure-base behavior and working models: New growing points of attachment theory and research. Monographs of the Society for Research in Child Development. 60(2-3, Serial No. 244), $179-196$.

*Lehman, E. B., Denham, S., Moser, M. H., \& Reeves, S. L. (1992). Soft object and pacifier attachments in young children: The role of security of attachment to the mother. Journal of Child Psychology and Psychiatry, 33, 1205-1215.

*Lieberman, A. F., Weston, D. R., \& Pawl, J. H. (1991). Preventive intervention and outcome with anxiously attached dyads. Child Development, 62, 199-209.

Light, R. J., \& Pillemer, D. B. (1984). Summing up: The science of reviewing research. Cambridge, MA: Harvard University Press.

*Lundy, B. L. (2002). Paternal socio-psychological factors and infant attachment: The mediating role of synchrony in father-infant interactions. Infant Behavior $\mathcal{E}$ Development, 25, 221-236.

Lyons-Ruth, K., \& Jacobvitz, D. (1999). Attachment disorganization: Unresolved loss, relational violence, and 
lapses in behavioral and attentional strategies. In J. Cassidy \& P. R. Shaver (Eds.), Handbook of attachment: Theory, research, and clinical applications (pp. 520-554). New York: Guilford Press.

Main, M. (1990). Cross-cultural studies of attachment organization: Recent studies, changing methodologies, and the concept of conditional strategies. Human Development, 33, 48-61.

Main, M. (1999). Epilogue. Attachment theory: Eighteen points with suggestions for future studies. In J. Cassidy \& P. R. Shaver (Eds.), Handbook of attachment: Theory, research, and clinical applications (pp. 845-889). New York: Guilford Press.

Main, M., \& Cassidy, J. (1988). Categories of response to reunion with parent at age six: Predictable from infant attachment classifications and stable over a one-month period. Developmental Psychology, 24, 415-426.

Main, M., \& Solomon, M. (1990). Procedures for identifying infants as disorganized/disoriented during the Ainsworth Strange Situation. In M. T. Greenberg, D. Cicchetti, \& E. M. Cummings (Eds.), Attachment in the preschool years (pp. 121-160). Chicago: University of Chicago Press.

*Mangelsdorf, S. C., Plunkett, J. W., Dedrick, C. F., \& Berlin, M. (1996). Attachment security in very low birth weight infants. Developmental Psychology, 32, 914-920.

*Marsh, B. P. (1994). Quality of attachment and reunion behaviors associated with early child care. Unpublished doctoral dissertation, University of Pittsburgh.

*McCullough, P. A. (2000). Effects of prenatal drug exposure and caregiving environment on infant development. Dissertation Abstracts International: $A$. The Humanities and Social Sciences, 60, 4319.

*Moran, G., Pederson, D. R., Pettit, P., \& Krupka, A. (1992). Maternal sensitivity and infant-mother attachment in a developmentally delayed sample. Infant Behavior and Development, 15, 427-442.

*Moss, E., Gosselin, C., Rousseau, D., \& Dumont, M. (1997). Attachment and joint problem solving experiences during the preschool period. Social Development, 6 , $1-17$.

Mullen, B. (1989). Advanced basic meta-analysis. Hillsdale, NJ: Erlbaum.

*Nakagawa, M., Teti, D. M., \& Lamb, M. E. (1992). An ecological study of child-mother attachments among Japanese Sojourners in the United States. Developmental Psychology, 28, 584-592.

*National Institute of Child Health and Human Development Early Child Care Research Network. (1999). NICHD Study of Early Child Care. Phase I [CD-ROM]. Available at http://public.rti.org/secc/.

*O'Connor, M. J., Kogan, N., \& Findlay, R. (2002). Prenatal alcohol exposure and attachment behavior in children. Alcoholism-Clinical and Experimental Research, 26, $1592-1602$.

*Oppenheim, D. (1997). The attachment doll-play interview for preschoolers. International Journal of Behavioral Development, 20, 681-697.
*Parent, S., \& Moss, E. (1995). L'influence de l'attachement mere-enfant et des habilites verbales de l'enfant $\mathrm{d}^{\prime}$ age prescolaire sur l'etayage maternel dans une tache de planification simple [The influence of mother-child attachment and preschool child's verbal skills on maternal scaffolding in a simple planning task]. Enfance, $317-335$.

*Park, K. A. (1992). Preschoolers' reactions to loss of a best friend: Developmental trends and individual differences. Child Study Journal, 22, 233-252.

* Park, K. A. (2001). Attachment security of 12 month old Korean infants: Relations with maternal sensitivity and infants' temperament. Early Child Development and Care, 167, 27-38.

*Park, K. A., \& Waters, E. (1989). Security of attachment and preschool friendships. Child Development, 60, 1076-1081.

*Pederson, D. R., Gleason, K. E., Moran, G., \& Bento, S. (1998). Maternal attachment representations, maternal sensitivity, and infant-mother attachment. Developmental Psychology, 34, 925-933.

*Pederson, D. R., \& Moran, G. (1996). Expressions of the attachment relationship outside of the Strange Situation. Child Development, 67, 915-927.

*Pederson, D. R., Moran, G., Bento, S., \& Buckland, G. (1992, July). Maternal sensitivity and attachment security: Concordance of home- and lab-based measures. Poster session presented at the International Conference on Infant Studies, Miami Beach, FL.

*Pederson, D. R., Moran, G., Sitko, C., Campbell, K., Ghesquire, K., \& Acton, H. (1990). Maternal sensitivity, and the security of infant-mother attachment: A Q-sort study. Child Development, 61, 1974-1983.

* Peterson, N. J., Drotar, D., Olness, K., Guay, L., \& KiziriMayengo, R. (2001). The relationship of maternal and child HIV infection to security of attachment among Ugandan infants. Child Psychiatry and Human Development, 32, 3-17.

*Petrie, A. J., \& Davidson, I. F. W. K. (1995). Toward a grounded theory of parent preschool involvement. Early Child Development and Care, 111, 5-17.

*Phonyotin, P. (1994). Relations between young Thai children's attachment and their reunion behavior when picked up by their mothers from early childhood settings. Unpublished doctoral dissertation, University of Missouri.

* Pianta, R. C., Nimetz, S. L., \& Bennett, E. (1997). Motherchild relationships, teacher-child relationships, and school outcomes in preschool and kindergarten. Early Childhood Research Quarterly, 12, 263-280.

*Pierrehumbert, B., Muehlemann, I., Antonietti, J. P., \& Sieye, A. (1995). Etude de validation d'une version francophone $\mathrm{du}$ "Q-sort" d'attachement de Water et Deane. Enfance, 315.

*Pool, M. M., Bijleveld, C. C. J. H., \& Tavecchio, L. W. C. (2000). The effect of same-age and mixed-age grouping in day care on parent-child attachment security. Social Behavior and Personality, 28, 595-602. 
*Posada, G., Gao, Y., Wu, F., Posada, R., Tascon, M. Schoelmerich, A., et al. (1995). The secure base phenomenon across cultures: Children's behavior, mother's preferences, and experts' concepts. In E. Waters, B. E. Vaughn, G. Posada, \& K. Kondo-Ikemura (Eds.), Caregiving, cultural, and cognitive perspectives on securebase behavior and working models: New growing points of attachment theory and research. Monographs of the Society for Research in Child Development, 60(2-3, Serial No. 244), 27-48

*Posada, G., Jacobs, A., Carbonell, O. A., Alzate, G., Bustamante, M. R., \& Arenas, A. (1999). Maternal care and attachment security in ordinary and emegency contexts. Developmental Psychology, 35, 1379-1388.

*Posada, G., Jacobs, A., Richmond, M. K., Carbonell, O. A., Alzate, G., Bustamante, M. R., et al. (2002). Maternal caregiving and infant security in two cultures. Developmental Psychology, 38, 67-78.

*Posada, G., Waters, E., Crowell, J. A., \& Lay, K. L. (1995). Is it easier to use a secure mother as a secure base? Attachment Q-sort correlates of the Adult Attachment Interview. In E. Waters, B. E. Vaughn, G. Posada, \& K. Kondo-Ikemura (Eds.), Constructs, cultures and caregiving: New growing points in attachment theory and research. Monographs of the Society for Research in Child Development, 60(Serial No. 244), $133-145$.

*Preski, S., \& Walker, L. O. (1992, July). Maternal report of infant attachment security: Measurement considerations. Poster presented at the 8th International Conference on Infant Studies, Miami Beach, FL.

*Puentes-Neuman, G. (2000). Toddlers' social coordination with an unfamiliar peer: Patternings of attachment, temperament, and coping during dyadic exchange. Dissertation Abstracts International: Section B. The Physical Sciences and Engineering, 61, 1674.

*Roggman, L. A., Hart, A. D., \& Jump, V. K. (1996, April). Attachment in relation to parenting stress and temperament: Longitudinal effects from 10 to 18 months. Paper presented at the International Conference on Infant Studies, Montreal, Canada.

Rosenthal, R. (1991). Meta-analytic procedures for social research. Beverly Hills, CA: Sage.

Rosenthal, R. (1995). Writing meta-analytic reviews. Psychological Bulletin, 118, 183-192.

Rutgers, A. H., Bakermans-Kranenburg, M. J., \& van IJzendoorn, M. H. (2004). Attachment in autistic children: The Attachment Q-Set. Manuscript in prepartion.

*Sagi, A., van IJzendoorn, M. H., Aviezer, O., Donnell, F., Koren-Karie, N., Joels, T., et al. (1995). Attachments in multiple-caregiver and multiple-infant environment: The case of the Israeli kibbutzim. In E. Waters, B. E. Vaughn, G. Posada, \& K. Kondo-Ikemura (Eds.), Caregiving, cultural, and cognitive perspectives on securebase behavior and working models: New growing points of attachment theory and research. Monographs of the Society for Research in Child Development, 60(2-3, Serial No. 244), $71-91$.
*Schiller, M. M., Seifer, R., Resnick, S., \& Riordan, K. (1995, April). Temperament, maternal interaction style and attachment in the first year of life. Paper presented at the meeting of the Society for Research in Child Development, Indianapolis, IN.

*Schmidt, M. E. (1998). Predicting kindergartners' behavioral and social outcomes from security of attachment with mother at age 3. Dissertation Abstracts International: B. The Physical Sciences and Engineering, 59, 1394.

Schneider, B. H., Atkinson, L. E., \& Tardif, C. (2001). Child - parent attachment and children's peer relations: A quantitative review. Developmental Psychology, 37, 86-100.

*Schneider-Rosen, K., \& Burke, P. B. (1999). Multiple attachment relationships within families: Mothers and fathers with two young children. Developmental Psychology, 35, 436-441.

*Schoelmerich, A., Fracasso, M. P., Lamb, M. E., \& Broberg, A. G. (1995). Interactional harmony at 7 and 10 months of age predicts security of attachment as measured by Q-sort ratings. Social Development, 4, 62-74.

*Schoelmerich, A., \& van Aken, M. A. G. (1996). Attachment security and maternal concepts of ideal children in Northern and Southern Germany. International Journal of Behavioral Development, 19, 725-738.

*Seifer, R., Schiller, M., Sameroff, A. J., Resnick, S., \& Riordan, K. (1996). Attachment, maternal sensitivity, and infant temperament during the first year of life. Developmental Psychology, 32, 12-25.

* Silverman, N. (1990). Attachment, maternal behavior and preschool competence at age three. Unpublished doctoral dissertation, Boston University.

Solomon, J., \& George, C. (1999). The measurement of attachment security in infancy and childhood. In J. Cassidy \& P. Shaver (Eds.), Handbook of attachment theory and research (pp. 287-316). New York: Guilford Press.

*Solomon, J., George, C., \& Silverman, N. (1987). Maternal caretaking Q-sort: Describing age-related changes in motherchild interaction. Unpublished manuscript.

Sroufe, L. A. (1985). Attachment classification from the perspective of infant - caregiver relationships and infant temperament. Child Development, 56, 1-14.

Sroufe, L. A. (1988). The role of infant-caregiver attachment in development. In J. Belsky \& T. Nezworski (Eds.), Clinical implications of attachment (pp. 18-40). Hillsdale, NJ: Erlbaum.

*Stevenson-Hinde, J., \& Shouldice, A. (1990). Fear and attachment in 2.5-year-olds. British Journal of Developmental Psychology, 8, 319-333.

Stevenson-Hinde, J., \& Verschueren, K. (2002). Attachment in childhood. In P. K. Smith \& C. H. Hart (Eds.), Handbook of childhood social development (pp. 182-204). Oxford, England: Blackwell.

*Strayer, F. F., Verissimo, M., Vaughn, B. E., \& Howes, C. (1995). A quantitative approach to the description and classification of primary social relationships. In E. Waters, B. E. Vaughn, G. Posada, \& K. Kondo-Ikemura 
(Eds.), Caregiving, cultural, and cognitive perspectives on secure-base behavior and working models: New growing points of attachment theory and research. Monographs of the Society for Research in Child Development, 60(2-3, Serial No. 244), 49-70

*Symons, D. K., Clark, S., Isaksen, G., \& Marshall, J. (1998). Stability of Q-sort attachment security from age two to five. Infant Behavior and Development, 21, 785-791.

*Symons, D. K., Noiles, L. N., \& Richards, C. M. (1995, March). Maternal sensitivity and concurrent infant-mother attachment security at age two. Paper presented at the Society for Research in Child Development, Indianapolis, IN.

Tabachnick, B. G., \& Fidell, L. S. (2001). Using multivariate statistics. New York: Harper \& Row.

*Tarabulsy, G. M., \& Moran, G. (1997). Similarities and differences in mothers' and observers' descriptions of attachment behaviors. International Journal of Behavioral Development, 21, 599-619.

*Tessier, R., Tarabulsy, G. M., Larin, S., Josee, L., Gagon, M. F., \& Johanne, T. (2002). A home-based description of attachment in physically disabled infants. Social Development, 11, 147-165.

*Teti, D. M., \& Ablard, K. E. (1989). Security of attachment and infant-sibling relationships: A laboratory study. Child Development, 60, 1519-1528.

*Teti, D. M., \& McGourty, S. (1996). Using mothers versus trained observers in assessing children's secure base behavior: Theoretical and methodological considerations. Child Development, 67, 597-605.

*Teti, D. M., Nakagawa, M., Das, R., \& Wirth, O. (1991). Security of attachment between preschoolers and their mothers: Relations among social interaction, parenting stress, and mother's sorts of the Attachment Q-Set. Developmental Psychology, 27, 440-447.

*Teti, D. M., Sakin, J., Kucera, E., \& Corns, K. M. (1996). And baby makes four: Predictors of attachment security among preschool-aged firstborns during the transition to siblinghood. Child Development, 67, 579-596.

Thompson, R. A. (1990). Vulnerability in research-A developmental perspective on research risk. Child Development, 61, 1-16.

Thompson, R. A. (1999). Early attachment and later development. In J. Cassidy \& P. Shaver (Eds.), Handbook of attachment theory and research (pp. 265-286). New York: Guilford Press.

*Trudel, M. (1988). Developmental changes in temperament. Unpublished doctoral dissertation, University of Quebec at Montreal.

*Van Bakel, H. J. A., \& Riksen-Walraven, J. M. (2002). Parenting and development of one-year-olds: Links with parental, contextual, and child characteristics. Child Development, 73, 256-273.

*Van Bakel, H. J. A., \& Riksen-Walraven, J. M. A. (in press) AQS security scores: What do they represent? A study in construct validation. Infant Mental Health Journal.

*Van Dam, M., \& van IJzendoorn, M. H. (1988). Measuring attachment security: Concurrent and predictive validity of the Parental Attachment Q-set. Journal of Genetic Pyschology, 149, 447-457.

van IJzendoorn, M. H. (1995). Adult attachment representations, parental responsiveness, and infant attachment. A meta-analysis on the predictive validity of the Adult Attachment Interview. Psychological Bulletin, 117, $387-403$.

van IJzendoorn, M. H., \& De Wolff, M. W. E. (1997). In search of the absent father. Meta-analyses of infantfather attachment. A rejoinder to our discussants. Child Development, 68, 604-609.

van IJzendoorn, M. H., \& Sagi, A. (1999). Cross-cultural patterns of attachment: Universal and contextual dimensions. In J. Cassidy \& P. Shaver (Eds.), Handbook of attachment theory and research (pp. 265-286). New York: Guilford Press.

Vaughn, B. E., \& Bost, K. K. (1999). Attachment and temperament: Redundant, independent, or interacting influences on interpersonal adaptation and personality development. In J. Cassidy \& P. Shaver (Eds.), Handbook of attachment theory and research (pp. 198-225). New York: Guilford Press.

Vaughn, B., Egeland, B., Sroufe, L. A., \& Waters, E. (1979). Individual differences in infant-mother attachment at twelve and eighteen months: Stability and change in families under stress. Child Development, 50, 971-975.

Vaughn, B. E., Stevenson-Hinde, J., Waters, E., Kotsaftis, A., Lefever, G. B., Shouldice, A., et al. (1992). Attachment security and temperament in infancy and early childhood: Some conceptual clarifications. Developmental Psychology, 28, 463-473.

*Vaughn, B. E., Strayer, F. F., Jacques, M., Trudel, M., \& Seifer, R. (1991). Maternal descriptions of 2- and 3-year old children: A comparison of attachment Q-sorts in two socio-cultural communities. International Journal of Behavioral Development, 14, 249-271.

*Vaughn, B. E., \& Waters, E. (1990). Attachment behavior at home and in the laboratory: Q-sort observations and strange situation classifications of one-year-olds. Child Development, 61, 1965-1973.

*Vereijken, C. M. J. L. (1996). The mother-infant relationship in Japan: Attachment, dependency and amae. Capelle aan den IJsel, Netherlands: Labyrint Publication.

*Vereijken, C. M. J. L., Hanta, S., \& van Lieshout, C. F. M. (1997). Validity of attachment Q-sort descriptions by mothers: The Japanese case. Japanese Psychological Research, 39, 291-299.

*Vereijken, C. M. J. L., \& Kondo-Ikemura, K. (2004). Attachment security and maternal sensitivity in Japan: Mother and observer attachment $Q$-sorts related to maternal behaviors. Manuscript in preparation.

Vereijken, C. M. J. L., Meij, J. T. H., \& Riksen-Walraven, J. M. A. (2004). Validity of attachment Q-sort descriptions by mothers: The Dutch case. Manuscript in preparation.

*Vereijken, C. M. J. L., Riksen-Walraven, J. M., \& KondoIkemura, K. (1997). Maternal sensitivity and infant attachment security in Japan: A longitudinal study. International Journal of Behavioral Development, 21, 35-49. 
Vereijken, C. M. J. L., Riksen-Walraven, J. M. A., \& van Lieshout, C. F. M. (1997). Mother-infant relationship in Japan: Attachment, dependency, and amae. Journal of Cross Cultural Psychology, 28, 442-462.

*Vittorini, L. (2002). Agency in social interaction and its relations with attachment. Unpublished manuscript.

*Wachs, T. D., \& Desai, S. (1993). Parent-report measures of toddler temperament and attachment: Their relation to each other and to the social microenvironment. Infant Behavior and Development, 16, 391-396.

Waters, E., \& Deane, K. (1985). Defining and assessing individual differences in attachment relationships: Q-methodology and the organization of behavior in infancy and early childhood. In I. Bretherton \& E. Waters (Eds.), Growing points of attachment theory and research. Monographs of the Society for Research in Child Development, 50(Serial No. 209), 41-65.

Waters, E., Hamilton, C. E., \& Weinfield, N. S. (2000). The stability of attachment security from infancy to adolescence and early adulthood: General introduction. Child Development, 71, 678-683.

Waters, E., Vaughn, B. E., Posada, G., \& Kondo-Ikemura, K. (Eds.), (1995). Caregiving, cultural, and cognitive perspectives on secure-base behavior and working models: New growing points of attachment theory and research. Monographs of the Society for Research in Child Development, 60(2-3, Serial No. 244).

*Weiss, S. J., Wilson, P., Hertenstein, M. J., \& Campos, R. (2000). The tactile context of a mother's caregiving: Im- plications for attachment of low birth weight infants. Infant Behavior and Development, 23, 91-111.

*White, K. A. (1998). Attachment relationships during toddlerhood: Measurement perspectives and concurrent correlates. Dissertation Abstracts International: $B$. The Physical Sciences and Engineering, 58, 5169.

*Wood, J. J., Emmerson, N. A., \& Cowan, P. A. (in press). Is early attachment security carried forward into relationships with preschool peers? British Journal of Developmental Psychology.

*Woods, S., Shearsby, J., Onslow, M., \& Burnham, D. (2002). Psychological impact of the Lidcombe Program of early stuttering intervention. International Journal of Language E Communication Disorders, 37, 31-40.

*Wu, F., \& Zou, H. (1995). The association between attachment quality and peer relationships of preschool children. Acta Psychologica Sinica, 27, 434-441.

*Youngblade, L. M., Park, K. A., \& Belsky, J. (1993). Measurement of young children's close friendship: A comparison of two independent assessment systems and their associations with attachment security. International Journal of Behavioral Development, 16, $563-587$.

Zeijlmans van Emmichoven, I. A., van IJzendoorn, M. H., de Ruiter, C., \& Brosschot, J. F. (2003). Selective processing of threatening information: Effects of attachment representation and anxiety disorder on attention and memory. Development $\mathcal{E}$ Psychopathology, 15, $219-237$. 